\title{
LA REFORMA DE LA SUCESIÓN A LA CORONA, EN EL REINO UNIDO DE LA GRAN BRETAÑA Y NORTE DE IRLANDA, Y EN LOS «OTROS REINOS» DE LA COMMONWEALTH OF NATIONS
}

\author{
LEIRE ESCAJEDO SAN-EPIFANIO \\ Profesora Titular de Derecho Constitucional \\ Universidad del País Vasco ${ }^{1}$
}

\begin{abstract}
SUMARIO
I. El acuerdo de Perth como punto de partida del proceso de reforma de la sucesión a la corona en los reinos de la mancomunidad de naciones. II. Las reglas de sucesión al trono, antes de la reforma. III. El complicado abordaje de la reforma de la sucesión al trono en los reinos de la Commonwealth. IV. El proceso de reforma en el Reino Unido y el contenido de la ley aprobada por el parlamento. V. El proceso de reforma en los reinos de la Commonwealth de Oceanía. VI. El proceso de reforma en los reinos de la Commonwealth del continente americano. VII. Reflexiones finales.
\end{abstract}

\section{EL ACUERDO DE PERTH COMO PUNTO DE PARTIDA DEL PROCESO DE REFORMA DE LA SUCESIÓN A LA CORONA EN LOS REINOS DE LA MANCOMUNIDAD DE NACIONES}

$\mathrm{Al}$ abordar el fenómeno monárquico que, de algún modo, comparten los dieciséis Reinos de la Mancomunidad de Naciones es frecuente citar a Sidney Low quien explicaba que la gobernanza británica vive bajo un sistema de comprensiones tácitas que «no siempre se comprenden $»^{2}$. La Corona conserva significaciones

1 Grupo de Investigación Multilevel Constitutionalism: Governance, Diversity and Human Rights de la UPV/EHU y proyectos MINECO DER293-47774-P (2013-2017) y MINECO DER2017-86988-P (20172020), I.P. A. López Basaguren.

2 Citado de la obra The Gobernance of England (1904), por MCLEAN, What's Wrong with the British Constitution, Oxford University Press, 2010, p.viii y BonNEY, «Some constitutional issues concerning the installation of the Monarch», British Politics, vol. 7. N², 2012, p. 1641. 
tradicionales —incluso emotivas - para la Gran Bretaña, y ha venido representando, entre otros, la unidad frente al pluralismo jurídico-político, además de dar soporte tanto a la personalidad jurídica del Estado como, de algún modo, a la unidad y existencia política del pueblo ${ }^{3}$. Si históricamente este concepto había demostrado una importante multifuncionalidad y elasticidad en su adaptación a los cambios evolutivos ${ }^{4}$, qué decir de la profunda transformación que se produjo en la Corona a partir de mediados del siglo XX. En el proceso desvanecimiento del Imperio Británico surgen para el Monarca británico (Jorge V y VI, y especialmente Isabel $\mathrm{II}^{5}$ ) nuevos roles, separados claramente de la Corona Británica. En primer lugar, asume la Corona de nuevos Reinos, surgidos en los procesos de independencia. Como es sabido, el Reino Unido de la Gran Bretaña y Norte de Irlanda, cinco países de Oceanía (Nueva Zelanda, Australia, Papúa Nueva Guinea, Islas Salomón y Tuvalú) y diez países del continente americano (Canadá y los estados de Antigua y Barbuda, Bahamas, Barbados, Belice, Granada, Jamaica, San Cristóbal y Nieves, Santa Lucía y San Vicente y las Granadinas) tienen en la actualidad como Monarca y Jefa de Estado a la Reina Elizabeth Alexandra Mary Windsor, aunque ésta llegó a ser Reina en otros dieciséis Estados más ${ }^{6}$ Lo que vincula a estos Estados, que suman aproximadamente 130 millones de habitantes, no es ya una Corona Imperial unificada, sino 16 Coronas separadas entre las que existe una unión personal. El segundo de los roles en aparecer será el de la Jefatura de la Mancomunidad de Naciones, a la que sus 52 miembros actuales ${ }^{8}$-la mayoría de ellos repúblicas - se vinculan por su lealtad común a la Corona.

Hacía tiempo que, tanto en el Reino Unido como en otros Reinos, la preferencia del varón sobre la mujer en la misma línea y grado y otras previsiones de las normas de sucesión —en especial, las relativas a la exclusión de los católicosse veían en abstracto como un anacronismo discriminatorio ${ }^{9}$, difícil de justificar en las democracias modernas ${ }^{10}$. Entre 1979 y 2009 se presentaron en el Parlamento

3 García Pelayo, Derecho Constitucional Comparado, $8^{\text {a }}$ ed., Madrid, 1958, pp. 292-295.

4 Saunders, «The Concept of the Crown», Melbourne University Law Review, vol. 38, 2015, pp. 873-896.

5 A la Reina Victoria, Reina del Reino Unido y Emperatriz de la India —desde 1877— (1837-1901), le sucedieron: Eduardo VII (1901-1910), Jorge V (1910-1936), Eduardo VIII (durante menos de un año); Jorge VI (1936-1952), primer jefe de la Commonwealth, e Isabel II, desde 1952 hasta la fecha.

6 Hasta la década de los 60-70 había sido también monarca de los estados de Ghana, Nigeria, Sierra Leona, Tanganyika, Uganda, Kenia, Malawi, Mauricio, Sudáfrica, Gambia, Trinidad y Tobago, Guyana, Pakistán, Ceilán y Malta, hoy en día todos ellos repúblicas, y en 1987 dejó de ser reina de Fiji.

7 Phillips/ Jackson, Constitutional and Administrative Law, Jackson/ Leopold (eds.), Sweet \& Maxwell, Londres, 2001, 8 ed., pp. 36-023; WINTERTON, «The Evolution of a Separate Australian Crown», Monash University Law Review, 1993, n 19/1, pp. 2-21.

8 Vid. nota 32.

9 HunTER, "A more modern Crown: changing the rules of sucession in the Commonwealth Realms», Commonwealth Law Bulletin, vol. 38, n³, 2012, pp. 423-466, p. 424.

10 Trece de los 16 Reinos de la Mancomunidad de naciones ofrecen protección constitucional expresa a la libertad religiosa y a la igualdad de género. Así, la Carta Canadiense de Derechos y Libertades (desde 1982) y las Constituciones de Antigua y Barbuda (1981), Bahamas (1973), Barbados (2002), Belice (2000), 
británico más de 13 propuestas de reforma de estas normas ${ }^{11}$ y sólo razones de oportunidad política pueden explicar que las sucesivas mayorías parlamentarias se resistieran a abordar esta cuestión ${ }^{12}$. El compromiso ${ }^{13}$ de Guillermo y Catalina, actuales Duques de Cambridge, y la previsión de su futura descendencia fue lo que propició que en Octubre de 2011, durante la Reunión bianual de Jefes de Gobierno de la Mancomunidad de Naciones (Commonwealth Heads of Governments Meeting - CHOMG) los Jefes de Gobierno de los 16 Realms de la Commonwealth adoptaran el que se conoce como Acuerdo de Pert ${ }^{14}$. En él, y a propuesta del Reino Unido, se comprometieron reformar de forma simultánea sus legislaciones internas en los siguientes aspectos: 1) para todos los nacidos con posterioridad al $28 \mathrm{de}$ Octubre de 2011, y por tanto sin efectos retroactivos, quedaría derogada la preferencia del varón sobre la mujer en la línea de sucesión; 2) se derogaría, asimismo, la previsión de excluir de la línea de sucesión a los herederos que contrajesen matrimonio con católicos; y, 3) el número de personas en la línea de sucesión que estaban obligadas a solicitar permiso real para contraer matrimonio se limitaría a las seis primeras. A pesar de algunas críticas, no se propuso suprimir la prohibición de que un católico accediera al trono, habida cuenta de que quien accede al trono ostenta en algunos Reinos el título de Defensor(a) de la $\mathrm{Fe}^{15}$ y es cabeza de la Iglesia de Inglaterra ${ }^{16}$.

Con intención de evitar que aunque fuera por pequeños lapsos de tiempo las normas de sucesión a la Corona fueran divergentes en estos países, se hizo un especial esfuerzo de coordinación. El 2 de diciembre de 2012, dos días antes de que los Duques de Cambridge anunciaran su primer embarazo, el Gobierno Británico recibió formalmente la adhesión de los Realms a la reforma y comenzó su tramitación parlamentaria. El proceso de cambio de las normas de sucesión al trono en los 16 Reinos, superado un breve proceso judicial en Canadá y otras vicisitudes, terminó

Papúa Nueva Guinea, Granada (1973), Jamaica (1962), San Cristóbal y Nieves (1983), San Vicente y las Granadinas (1979), Islas Salomón (1987) y Tuvalú. Por su parte, Australia, Reino Unido y Nueva Zelanda ofrecen protección legal a la libertad religiosa y la igualdad de género.

11 Twomey, «El cambio de las normas sobre sucesión al trono», Teoría y Realidad Constitucional, $\mathrm{n}^{\circ} 31$, 2013, pp. 137-168, ofrece una panorámica de los diferentes proyectos y de los argumentos con base en los cuáles fueron rechazados en los diferentes debates parlamentarios, con detalladas referencias al UK Hansard.

12 Vid. Brazier, «Legislating about the Monarchy», Cambridge Law Journal, vol. 66/1, 2007, pp. 86-105 y detalle de los procesos en House of Commons Library Research Paper 09/24, Royal Marriages and Succession to the Crown Prevention of Discrimination Bill, de 7 de marzo de 2009.

13 El compromiso fue anunciado en noviembre de 2010 y la boda tuvo lugar en abril de 2011.

14 22nd Commonwealth Heads of Government Meeting (CHOGM), Perth Agreement, 28-30 de octubre de 2011, texto completo en World Heritage Enciclopedia Edition, self.gutemberg.org.

15 Título que el Papa León reconoció a Enrique VIII por su defensa de la Iglesia Católica y que, paradójicamente, se mantendría después de que dicho Rey rompiera con Roma (en 1534) y se fundase la Iglesia de Inglaterra.

16 En Rules of Royal Succession, The Stationery Office Limited, 7 de diciembre de 2011, Anexo I, Disponible en services.parliament.uk/bills. Vid. FERnÁNDEZ SEGADO, «El Régimen Político Británico. I La formación histórica de la Constitución Inglesa y los Principios políticos del régimen», Ferrando-Badía (coord.), Regímenes políticos Actuales, Tecnos, $3^{\text {a }}$ ed., Madrid, p. 108. 
oficialmente el 26 de marzo de $2015^{17}$. En este análisis jurídico constitucional del proceso se expondrán, en primer lugar, las normas de sucesión al trono previas al Acuerdo de Perth y las razones que explicaban el hecho de que éstas se hubieran mantenido prácticamente inalteradas desde el siglo XVIII. A continuación, y respecto de cada uno de los Reinos de la Mancomunidad, se abordarán los procesos de reforma y, en algunos casos, las particularidades surgidas en dichos procesos, incluyendo además una mención final sobre iniciativas y/o debates que se hubieran planteado sobre la cuestión republicana. Por claridad expositiva, los Reinos han sido agrupados por Continentes: en primer lugar, se expondrá la reforma abordada en el Reino Unido de la Gran Bretaña y Norte de Irlanda (IV); a continuación, las reformas realizadas en Oceanía (V); y, por último, las acometidas en América (VI). A modo de resumen, cabe anticipar que además del Parlamento de Westminster, seis de los restantes Reinos (Australia, Barbados, Canadá, San Vicente y las Granadinas, Nueva Zelanda y San Cristóbal y Nieves) legislaron específicamente - aunque cada uno con sus matices- para adaptarse a los nuevos cambios. Otros nueve Reinos, por el contrario, concluyeron que no era necesaria una reforma específica y se limitaron a tramitar una suerte de consentimiento o conformidad (assent) a la reforma promovida en el Parlamento británico; fue el caso de: Antigua y Barbuda, Bahamas, Belice, Granada, Jamaica, Papúa Nueva Guinea, Santa Lucía, Islas Salomón y Tuvalú.

\section{LAS REGLAS DE SUCESIÓN AL TRONO, ANTES DE LA REFORMA}

\section{Las reglas tradicionales de la sucesión al trono en la Gran Bretaña}

Con excepción de la breve experiencia republicana en tiempos de Cromwell, la Monarquía se cuenta en el Reino Unido como una historia ininterrumpida desde que el rey Egbert uniera a los ingleses bajo su gobierno (año 829). De las instituciones vivas en Europa, señala la doctrina, sólo el Papado es más antiguo que la Monarquía inglesa ${ }^{18}$. Hasta su reforma entre 2013 y 2015 las normas que regulaban la sucesión al trono de los Reinos de la Commonwealth se explicaban como resultado de dos factores característicos de la historia del Reino Unido: de una parte, la lenta evolución del Common Law y, de otra parte, determinadas modificaciones estatutarias ${ }^{19}$. La preferencia del varón sobre la mujer dentro del

17 Véase el Instrumento estatutario $2015 \mathrm{~N}^{\circ} 894$ (C. 56), Succession to the Crown Act 2013 (Commencement) Order 2015.

18 BARKer, La monarquía constitucional de la Gran Bretaña, Oxford University Press, 1943, p. 4; en el mismo sentido De Smith/ Brazier, Constitutional and Administrative Law, $8^{\mathrm{a}}$ ed, Penguin, Londres, 1998, pp. 120 y ss.

19 Brazier, «Legislating about the Monarchy», 2007, p. 86.; Gómez SÁNCHEZ, «La sucesión a la Corona», Rollnert Liern (Dir.), Las monarquias Europeas en el siglo XXI, Sanz y Torres, 2007, Madrid, pp. $150-151$. 
mismo grado y línea es una norma que desde los tiempos de la conquista normanda se venía aplicando a la transmisión hereditaria de las propiedades feuda$1 \mathrm{e}^{20}$. Sólo en algunos momentos históricos y como respuesta a algún acontecimiento en concreto se eludió la aplicación de esta norma en los procesos de sucesión al Trono $^{21}$. Por ejemplo, la exclusión de los católicos y de aquellos que contrajesen matrimonio con parejas católicas ${ }^{22}$ (aunque no de sus descendientes protestantes $^{23}$ ) es una previsión cuyo origen está en la Revolución Gloriosa de 1688. Fallecida la Reina Isabel I sin descendencia, el Rey Jacobo VI de Escocia le sucedió en el trono de Inglaterra como Jacobo I. Su hijo, Carlos I, fue ejecutado en tiempos de Cromwell y es fácil entender por qué en la Restauración de la Monarquía Carlos II aceptó dos normas (las Test Acts) que prácticamente excluían a los católicos de la vida pública. Su sucesor, sin embargo, Jacobo II de Inglaterra y VII de Escocia, decidió convertirse al catolicismo después de haber sido coronado (1685-1688), y fue depuesto en Revolución Gloriosa. La Declaración de Derechos de 1689 (Bill of Rights) proclamó que, con su intento de fuga, Jacobo II había abdicado del reino dejándolo vacante, y evitando al hijo mayor de Jacobo II el Parlamento ofreció la Corona a María II y Guillermo III, que ejercieron conjuntamente como soberanos. En aquel momento, y con la intención de evitar que reclamasen el trono Jacobo II o sus herederos católicos, el Parlamento de Inglaterra adoptó con rapidez determinadas normas, entre ellas la exigencia de juramento de preservar la religión establecida antes de ser coronado (introducida en la Coronation Oath Act, 1689). María y Guillermo fallecieron sin descendencia y Ana de Estuardo, hermana de María, accedió al trono desde marzo de 1702, primero como Reina de Inglaterra, Escocia de Irlanda, y desde 1707 en adelante como Reina de la Gran Bretaña e Irlanda, tras la aprobación del Acta de la Unión ${ }^{24}$. A la exclusión de los católicos se añadió entonces la exclusión de quienes contrajesen matrimonio con éstos, mediante el Acta de Precedencia de la Princesa Sofía de $1711^{25}$ (madre de Jorge I). Por su parte, la Royal Marriages Act (1772) incorporó una obligación de que las personas en la línea de sucesión solicitasen un permiso para contraer matrimonio, que no afectó a las princesas que contrajesen matrimonio con una familia extranjera. Los herederos mayores de 25 años, no obstante, podían

20 Lyon, Constitutional History of the United Kingdom, Cavendish, Londres, 2003, p. 100.

21 Vid. Lyon, «The Place of Women in European Royal Succession in the Middle Ages», Liverpool Law Review, 27, 2007, pp. 361; PAPWORTH, «The Succesion to the Throne Act: Modernising the Monarchy», The Modern Law Review, 76/6, 2013, pp. 1070-1093, 1075.

22 Vid ejemplos en Hunter, «A more modern Crown», cit., 2012, pp. 423 notas 2 y 3.

23 Bogdanor, The Monarchy and the Constitution, cit., 1995, pp. 54-55; HC RESEARCH PAPER 09/24, Royal Marriages and Succession, cit., 2008-2009, p. 29. 48-49.

24 Porras Ramírez, Principio democrático y función regia en la Constitución Normativa; Tecnos, 1995, pp.

25 Vid. Lyon, «The Place of Women in European Royal Succession in the Middle Ages», Liverpool Law Review, 27, 2007, pp. 361; PAPwORTH, "The Succesion to the Throne Act: Modernising the Monarchy», The Modern Law Review, 76/6, 2013, pp. 1070-1093, 1075. 
comunicar al Privy Council su intención de contraer matrimonio sin la autorización del soberano y contraer matrimonio en el año siguiente, siempre y cuando no se constatase oposición de ambas cámaras del parlamento. El Acta de la Unión con Irlanda (1800) no reformó las normas de la sucesión que han sido expuestas, sino que mantuvo los términos de la Unión entre Inglaterra y Escocia. Tampoco se produjeron más cambios hasta prácticamente el año 1910, cuando se actualizó la declaración a realizar en el acceso al trono.

\section{De la Corona Imperial hacia la moderna Commonwealth: el Estatuto de Westminster (1931) y la Declaración de Londres (1949)}

Ya en el siglo XX las normas de sucesión al trono de la Corona Británica se vieron afectadas con una norma, el Estatuto de Westminster, cuyo objetivo principal era el de reconocer a los seis Dominios autogobernados del Imperio británico ${ }^{26}$ un nuevo estatuto constitucional ${ }^{27}$. Eran los tiempos del reinado de Jorge V (19101936), y como continuación de los compromisos adquiridos en la Declaración de Balfour (1926) con este Estatuto se procedía, como decía su sobrenombre, a «ejecutar ciertas resoluciones aprobadas en las Conferencias Imperiales de 1926 y 1929». Con excepción de Terranova, que terminaría uniéndose a Canadá ${ }^{28}$, este Estatuto se considera el punto de origen la independencia de esos territorios, aunque en casos como los de Australia y Nueva Zelanda su ratificación se hizo esperar ${ }^{29}$. Este es también el punto de partida de un fenómeno que se describe como de disgregación de la Corona, en el que el Monarca pasará de ser titular de una Corona Imperial a reinar sobre múltiples Reinos. Jorge VI, además de Rey de la Gran Bretaña y Emperador de la India, será Rey de los antiguos Dominios y su hija, Isabel II, llegará a ser Monarca de un total de 32 Reinos, la mitad de ellos hoy repúblicas.

El Estatuto de Westminster tendrá, entre otras cosas, implicaciones directas para cualquier futura modificación de las normas de sucesión a la Corona. De una parte, y en términos generales, estableció que ninguna norma aprobada por el Parlamento británico con posterioridad al Estatuto de Westminster podría aplicarse a los citados dominios a menos que éstos consintieran dicha norma. De otra parte, y por si hubiera lugar a dudas, especificó además en su Preámbulo que «la Corona es el símbolo de la libre asociación de los miembros de la Mancomunidad Británica de

26 Dominio de Canadá, la Mancomunidad de Australia, el Estado Libre de Irlanda, el Dominio de Terranova, el Dominio de Nueva Zelanda y la Unión Sudafricana.

27 Estatuto de Westminster de 11 de diciembre de 1931, sobre las Relaciones del Reino Unido de Gran Bretaña con los dominios de la Commonwealth. Texto en español en Daranas Peláez, Las Constituciones Europeas, vol I., Ed. Nacional, Madrid, p. 951.

28 Terranova, como es sabido, nunca llegó a aprobar el Estatuto de Westminster. En 1934, a petición de su gobierno, el Reino Unido reasumió su autoridad directa sobre el dominio y la mantuvo hasta que Terranova se convirtió en provincia canadiense (1949).

29 Australia lo ratificó en 1942 y Nueva Zelanda en 1947. 
Naciones, que se encuentran unidos por su lealtad común a aquella» y que cualquier modificación de la normativa de sucesión al trono o de los títulos reales habría «de obtener el asentimiento, tanto de los Parlamentos de todos los Dominios, como del Parlamento del Reino Unido» ${ }^{30}$.

Para comprender la evolución de la Commonwealth hasta el Acuerdo de Perth es importante tener en cuenta dos acontecimientos más. El primero de ellos fue el de la abdicación de Eduardo VIII, que reinó durante poco más de 11 meses (de enero a diciembre de 1936). Aquel fue el primer momento histórico en el que se activó la aplicación del Estatuto de Westminster ${ }^{31}$ respecto de la sucesión al Trono y en 2011 algunas voces lo verán como un precedente a tener en cuenta en los procesos de reforma. Un segundo acontecimiento clave fue el de Declaración de Londres de 1949. Respecto a la abdicación de Eduardo VIII, como es sabido éste quería contraer matrimonio con Wallis Simpson y hubo una primera consulta a los Primeros Ministros de la Commonwealth sobre la posibilidad de recurrir a un matrimonio morganático. Rechazada esta opción, Eduardo VIII abdicó y fue entonces cuando se solicitó el asentimiento de los Parlamentos de la Mancomunidad (entonces el Británico y los de Irlanda, Australia, Canadá, Sudáfrica y Nueva Zelanda) para aprobar la Ley de abdicación. Como notas discordantes cuya reiteración se querrá evitar tras el Acuerdo de Perth quedaron la simbólica demora de Irlanda, consecuencia de la cual tuvo un rey distinto al resto durante 24 horas, y la decisión de Sudáfrica de aprobar la abdicación, en vez de asentirla.

El segundo de los acontecimientos, la elaboración de la Declaración de Londres de 1949, representa el inicio de la que se describe como moderna Mancomunidad de Naciones. Esta Commonwealth pierde el calificativo de británica, como simbólico hecho diferencial respecto de la antigua Mancomunidad Británica de Naciones, formada por el Reino Unido y los Dominios previos a 1945. Uno de los cinco primeros Dominios, Irlanda, se proclama como república independiente y abandona la Mancomunidad y prácticamente al mismo tiempo la India expresa su deseo de independizarse y constituirse en república aunque, en este segundo caso, sin intención de abandonar la Mancomunidad. Sin obviar la preocupación por futuros abandonos, será la propuesta de la India la que impulsó definitivamente la Declaración de Londres, que persiguió dar forma al tipo de adhesión que los países republicanos mantendrían con la Commonwealth. En dicha Declaración se describe la Mancomunidad como una libre asociación de miembros independientes cuya Jefatura correspondía, en aquel entonces, al rey Jorge VI. En las décadas siguientes el número de países independientes fue en aumento hasta llegar — con algunos abandonos definitivos y otros intermitentes - a los 52 miembros actuales, que tienen una población que supera, repartida en los cinco continentes, los dos mil

30 Jennings, The British Constitution, Cambridge University Press, reimpresión de 1971, p. 122.

31 En 1953, por su parte, se acordó el cambio de las normas sobre el estilo y los títulos reales. 
millones de habitantes ${ }^{32}$. Siguiendo el precedente de India, muchos de los nuevos Estados se constituyeron como repúblicas o como monarquías con un rey propio, pero otros nuevos Estados — doce en total - acogieron constitucionalmente a Isabel de Windsor como Monarca. Ése será el escenario de aplicación del Acuerdo de Perth.

\section{El efecto inmediato de la implementación del Acuerdo de Perth}

Antes de entrar en otras cuestiones, ¿cuáles han sido los efectos más inmediatos de la entrada en vigor de la reforma de las normas de la sucesión el trono, en 2015? Hasta el nacimiento de Jorge y Carlota, hijos de los Duques de Cambridge, las consecuencias de la reforma de las normas de sucesión fueron limitadas. Los hijos de Davina Lewis, primogénita de los Duques de Gloucester, de nombres Senna (mujer, nacida en 2010) y Tāne (varón, nacido en 2012) fueron las únicas personas cuyas posiciones en la línea de sucesión al trono se vieron inmediatamente afectadas por la reforma. Senna, la hija mayor, se mantuvo por delante de su hermano varón, por haber nacido éste después de la firma del Acuerdo de Perth. La previsión no afectó, sin embargo, a la Princesa Real Ana, segunda hija de la Reina Isabel II, que no pasa a preceder a sus hermanos menores Andrés - Duque de York-y Eduardo - Conde de Wessex — ni a la descendencia de éstos, porque, como ya se ha dicho, se convino en que este apartado del Acuerdo de Perth no tendría efectos retroactivos.

Otros efectos de la entrada en vigor de las normas se refieren a las autorizaciones reales de matrimonio y a las consecuencias de contraer matrimonio con católicos. A la entrada en vigor del Acuerdo de Perth, la Princesa Eugenia dejó de necesitar autorización de su abuela para el matrimonio, y la Princesa Beatriz dejó de necesitarlo a partir del nacimiento de la segunda hija de los Duques de Cambridge - Carlota—. Por otra parte y también como consecuencia de la reforma realizada, el Príncipe Michael de Kent ${ }^{33}$, el primer primo de la Reina, retornó a la línea de sucesión, tras haber sido excluido cuando cinco décadas atrás contrajo matrimonio con su mujer católica; también se vieron positivamente afectados por la norma su hijo y sus nietos.

32 Son miembros de la Commonwealth 3 países europeos (Reino Unido, Malta y Chipre); 13 países americanos (Antigua y Barbuda, Bahamas, Barbados, Belize, Canadá, Dominica, Granada, Guyana, Jamaica, San Cristóbal y Nieves, San Vicente y las Granadinas, Santa Lucía, Trinidad y Tobago); 11 de Oceanía (Australia, Fiji, Kiribati, Islas Salomón, Nauru, Nueva Zelanda, Papúa Nueva Guinea, Samoa, Seychelles, Tuvalú y Vanuatu); 7 de Asia (Bangladesh, Brunei, India, Malasia, Pakistán, Singapur y Sri Lanka) y 18 de África (Botsuana, Camerún, Ghana, Kenia, Lesoto, Malaui, Mauricio, Mozambique, Namibia, Nigeria, Ruanda, Sierra Leona, Suazilandia, Sudáfrica, Tanzania, Tonga, Uganda y Zambia).

33 Fue excluido de la sucesión al trono en 1978. Vd. D’Oliveira, «The State of the European Union's Monarchies. The EU and Its Monarchies: Influences and Frictions», European Consitutional Law Review 8, 2012, pp. 63-81, p. 74. 


\section{EL COMPLICADO ABORDAJE DE LA REFORMA DE LA SUCESIÓN AL TRONO EN LOS REINOS DE LA COMMONWEALTH}

Como ya se ha dicho, existía un consenso extendido sobre la necesidad de que la monarquía británica y, por extensión la de los Realms, se adaptasen a los nuevos tiempos ${ }^{34}$, pero dos tipos de razones justificaban su posposición: de una parte razones de oportunidad; y, de otra, dos preocupaciones jurídico-constitucionales que de algún modo afectaban también al cómo realizar sin excesivos sobresaltos una reforma de tal magnitud ${ }^{35}$. La primera de las preocupaciones surge en torno a la flexibilidad del concepto de la Corona. Esta flexibilidad había contribuido significativamente al proceso de evolución desde la Corona Imperial hacia la Commonwealth, pero en el escenario del siglo XXI dificultaba la resolución de importantes cuestiones sobre la naturaleza y el enmarque constitucional de los roles atribuidos a la Reina Isabel en los dieciséis Reinos y en la Mancomunidad. La segunda preocupación, no menos importante, eran los interrogantes sobre el modo de proceder a reformar, respecto de la Commonwealth del siglo XXI, unas previsiones normativas que siglos atrás se habían creado únicamente respecto de la Gran Bretaña.

\section{Sobre la oportunidad política de la reforma de la sucesión al trono en la Commonwealth}

Entrando en las cuestiones de oportunidad, es comprensible que hasta la boda de Guillermo, Duque de Cambridge, la reforma de las normas de sucesión se viera como algo conveniente, aunque no urgente. La claridad en la línea de sucesión de Isabel II (cuyos primeros herederos eran varones y protestantes) hacia innecesario abrir un escenario en el que, más allá de eliminar la preferencia del varón sobre la mujer, era posible que surgieran consecuencias imprevistas. Ello explica también porque con el Acuerdo de Perth se persiguió abrir a la reforma única y exclusivamente a lo que se consideró imprescindible para garantizar que entre los futuros hijos de los Duques de Cambridge ya no tendría aplicación la prioridad del varón sobre la mujer en la misma línea y grado. Un debate sobre la sucesión a la Corona podría dar pie, obviamente, a cuestionar el sentido de mantener no ya un Monarca ausente $e^{36}$ sino, incluso, una institución monárquica en pleno siglo

34 Pimlotт, The Queen: A Biography of Elizabeth II, Londres, 1996, pp. 558-559 y Bogdanor, The Monarchy and the Constitution, Oxford, 1995, p. 303.

35 Walters, «Succesion to the Throne and Architecture of the Constitution of Canada», BÉDARD/ LaGassé (eds.), The Crown and the Parliament, 2015, p. 263-264.

36 Vid. Fraenkel, «Governors-General during Pacific Island constitutional crises and the role of Crown», Commonwealth and Comparative Politics, 2016, 54:1, pp. 1-22. 
XXI. De hecho la mayoría de los miembros de la Commonwealth habían ido progresando hacia formas de gobierno republicanas y, en algunos casos, se habían establecido monarquías propias -a las que la literatura se refiere como indígenas ${ }^{37}$.

El paso del tiempo no había borrado las tensiones vividas en tiempos de la abdicación de Eduardo VIII, cuyo matrimonio con Wallis Simpson, una mujer norteamericana y divorciada, fue visto como un potencial peligro para el nuevo marco de relación instaurado en la Mancomunidad Británica de Naciones. «Cualquier cataclismo en la Corona - diría el primer Ministro Baldwin en 1935- bará que el Imperio se desvanezca junto a ella» ${ }^{38} \mathrm{y}$, de hecho, en países como Canadá se llegó a decir que la Corona no era ya un vínculo necesario entre los países de la Commonwealth, sino más bien un elemento ornamental del Reino Unido que en poco tiempo dejaría de tener significado en el exterior ${ }^{39}$. Se sabía, además, que las encuestas - las más recientes de 2008 - reflejaban que la mayoría de los ciudadanos de Australia, cerca de la mayoría de los de Canadá y aproximadamente un treinta por ciento de los neozelandeses se mostraban favorables a avanzar hacia una república. Faltaba, cierto es, un consenso sobre cuál habría de ser el nuevo modelo de Jefatura de Estado ${ }^{40}$ y los ciudadanos mostraban, asimismo, cierta preocupación por el impacto que en el status internacional del país pudiera tener prescindir de ese simbólico vínculo con Gran Bretaña ${ }^{41}$, pero los jefes de gobierno de los dieciséis Reinos eran muy conscientes del reto al que se enfrentaban. Tampoco se perdían de vista la edad de la Reina Isabel, nacida en 1926, y el hecho de que un porcentaje importante de los encuestados en Australia y Canadá hubieran expresado en 2005-2006 que los vínculos con la Corona «deberían expirar al fallecer Isabel de Windsor», quizá por la distancia que se aprecia entre su figura y la de su hijo Carlos, el Príncipe de Gales.

\section{El flexible concepto de Corona en la Commonwealth}

Además de razones de oportunidad política, preocupaba y mucho la ausencia de claridad material y formal del conjunto normativo que estaba en vigor. Un conjunto de normas de la Corona inglesa, en su mayoría de finales del siglo XVII y principios del XVIII, había pasado a ser también legislación doméstica de los otros 15 Realms y, por si fuera poco, lo había hecho en formas diferentes. Desde el punto de vista jurídico-constitucional, tampoco estaban clarificados los roles que, en plural, habían ido asumiendo en el proceso de descolonización primero el

37 Vid. supra, nota 6.

38 Murphy, Monarchy and the End of Empire, cit., 2015, pp. 25-26.

39 Murphy, Monarchy and the End of Empire, cit., 2015, pp. 30-31.

40 Boyce, The Queen's Other Realms, cit., 2008, pp. 209-210.

41 Boyce, The Queen's Other Realms, cit., 2008, pV. 
Rey Jorge VI y posteriormente la Reina Isabel II; roles que ejercían, de una parte, respecto de la Mancomunidad de Naciones, en su conjunto, y, de otra y separadamente, respecto de cada uno de los Realms. En este orden de cosas, a finales del siglo XIX y principios del XX, un importante número de académicos veía la Corona de la Mancomunidad Británica de Naciones como algo indivisible, a pesar de que los Dominios de Canadá, Australia, Nueva Zelanda, Sudáfrica y Terranova tenían ya un gobierno propio. Explica Hunter que los gobernadores generales locales actuaban bajo el consejo de los ministros coloniales, pero en asuntos imperiales mantenían el vinculo con Westminster. Evidencia de ello fue que cuando el Reino Unido declaró la guerra en 1914, todos los Dominios estuvieron automáticamente en guerra ${ }^{42}$.

Progresivamente, sin embargo, los Dominios se convirtieron en naciones independientes y fueron adquiriendo una creciente autonomía en la gestión de los asuntos internacionales. Así se llegó a la Conferencia Imperial de 1926, celebrada en Londres ${ }^{43}$. Junto con el reconocimiento de la igualdad estatutaria de todas las comunidades de la Mancomunidad, se reconoció que los Gobernadores Generales ocupaban respecto de los Dominios la misma posición que el Monarca respecto al Reino Unido, y que no habían de ser entendidos como representantes o agentes del gobierno de Reino Unido ${ }^{44}$. Dos factores propiciaron la urgencia de dicha Conferencia. De una parte, la exigencia del General Hertzog de que Sudáfrica fuese formalmente reconocida como independiente (1924); de otra, la crisis surgida en Canadá, cuando el Gobernador General (Lord Byng) rehusó disolver el parlamento a petición del primer ministro (Mackenzie King), y este último solicitó que el Gobernador General dejase de ser un representante del gobierno británico en Canadá ${ }^{45}$. Bajo la presidencia del primer ministro británico, Arthur Balfour, un Comité especial de Relaciones Inter-Imperiales abordó las cuestiones constitucionales $^{46}$. En la que se conoce como Declaración o Informe de Balfour de 1926 se declaró la igualdad estatutaria entre la Gran Bretaña y los Dominios dentro de la Mancomunidad Británica de Naciones, destacando la total ausencia de subordinación entre unas y otras y sus vínculos por una lealtad común a la Corona. En implementación de dicha Declaración se hizo necesaria la elaboración de un conjunto de normas para el buen funcionamiento de la Mancomunidad y, reunidos en 1930, se estableció la base del Estatuto de Westminster ${ }^{47}$. Con dicho Estatuto se formalizó definitivamente el nuevo status de los Dominios ${ }^{48}$, y entró en vigor

42 Con más referencias, Hunter, «A more modern Crown», cit., 2012, p. 436; Bogdanor, The Monarchy, cit., 1995, pp. 242-243.

43 Murphy, Monarchy and the End of Empire, cit.,2015, p. 17-18.

44 Bogdanor, The Monarchy and the Constitution, cit., 1995, pp. 246-6; Winterton, "The Evolution», cit., pp. 8-16; HunTER, «A more modern Crown», cit., 2012, p. 437.

45 NaIRn, The Enchanted Glass: Britain and its Monarchy, Vintage, London, 1994, pp. xvi.

46 Murphy, Monarchy and the End of Empire, cit., 2015, p. 17-18.

47 Twomey, «El cambio», cit., TRC, 2013, p. 142.

48 UK. Statute of Westminster, 22 GEO. 5. CH. 4., disponible en www.legislation.gov.uk. 
en Canadá sin necesidad de ratificación, pero en Australia, Nueva Zelanda y Terranova quedó a la espera de una ratificación ${ }^{49}$.

La membresía de esta antigua Commonwealth se asentaba sobre tres elementos esenciales: la igualdad entre sus miembros, su libre asociación y su lealtad común a la Corona. Este último elemento, el de la lealtad a la Corona, había generado problemas en Irlanda y se quiso modificar mediante la Declaración de Londres (1949), interpretando que los miembros de la Commonwealth, en sus respectivos marcos constitucionales, no tenían porque establecer funciones específicas para el Jefe o Jefa de la Mancomunidad, porque eran cargos separados ${ }^{50}$. En este sentido la recién creada Oficina de Relaciones para la Mancomunidad de Naciones puso sobre la mesa una importante cuestión en tiempos de Jorge $\mathrm{VI}^{51}$ : «si la Mancomunidad no acepta una república en la que el Monarca no es parte de su Constitución, la lealtad a la Corona dejará de ser un vínculo entre los miembros de la Mancomunidad». Estados como Nueva Zelanda se mostraron reacios a diluir la idea de la lealtad a la Corona, pero habida cuenta de la relevancia de la India, de largo el segundo país más poblado del Planeta, y del precedente que se crearía para otras futuras repúblicas, se terminó por entender que esta cesión tenía una gran trascendencia ${ }^{52}$.

Esa solución pragmática, que para los Dominios tradicionales no afectaba a la simbólica autoridad de la Corona, fue vista como el origen de la moderna Mancomunidad de Naciones y síntoma de que ésta era capaz de evolucionar y de preservar el vínculo con territorios de África y Asia que no deseaban optar por un modelo monárquico tras su independencia. Sobre ese esquema, y con excepción de los territorios de ultramar británicos — British Overseas Territories ${ }^{53}$ _, se mantuvieron en la moderna Commonwealth la mayor parte de las antiguas colonias y protectorados que se independizaron en la Segunda Posguerra ${ }^{54}$. En esta línea, un acontecimiento muy relevante se produjo el 6 de febrero de 1952, cuando accedió al trono Isabel II. En torno a su Coronación (1953) quedó en evidencia el proceso de trans-

49 Así se hizo en Nueva Zelanda y Australia, en 1947 y 1942 respectivamente, pero no así en Terranova que en 1934 cedió su gobierno a Londres y posteriormente, en 1949, se unió a Canadá como décima provincia.

50 Stewart, Empire Lost: Britain, the Dominios and the Second World War, Continuum, Londres, 2008, p. 77.

51 Memorando de la Commonwealth Relations Office, «The Commonwealth Relationship», enero de 1949, DO 121/72, British National Archives, Kew.

52 Kumarasingham, «The 'Tropical Dominions': The appeal of dominion status in the decolonisation of India, Pakistan and Ceylon», Transactions of the Royal Historical Society, vol. 23, 2013, pp. 232-237.

53 Acrotiri y Dhekelia, Anguila, Bermudas, Islas Georgias del Sur y Sándwich del Sur, Islas Caimán, Islas Malvinas (Falkland), Islas Pitcairn, Islas Turcas y Caicos, Islas Vírgenes Británicas, Gibraltar, Montserrat, Santa Elena, Ascensión y Tristán de Acuña, Territorio Antártico Británico y Territorio Británico en el Océano Índico.

54 Birmania (Myanmar) y Adén son dos antiguas colonias que no se incorporaron a la Mancomunidad después de alcanzar la independencia; y entre los protectorados que quedarían fuera están Egipto (independiente en 1922), Irak (1932), Transjordania (1946), la Palestina Británica (parte de la cuál pasó a ser Israel en 1948), Sudán (1956), Somaliland (o Somalia británica, que unida a la italiana formó Somalia en 1960), Kuwait (1961), Bahréin (1971), Omán (1971), Qatar (1971) y los Emiratos Árabes Unidos (1971). 
formación que la Corona Británica había emprendido ya, y los seis meses en los que junto al Duque de Edimburgo recorrió la Commonwealth (1953-1954) se interpretaron como un esfuerzo por reafirmar la pervivencia del Imperio Británico y dotar de un nuevo contenido al cargo de Jefatura de la Mancomunidad de Naciones ${ }^{55}$. A juicio de Bogdanor ${ }^{56}$, las Royal Tittles Acts de 1953 regularizan la división de la Corona, toda vez que consecuencia de ellas cada uno de los Reinos (entonces Reino Unido, Canadá, Nueva Zelanda, Australia, Sudáfrica, Pakistán y Ceylán) comienza a usar títulos propios para referirse a su Monarca. Los títulos estarán compuestos por algún componente local (escogido por cada Reino) y seguido de las expresiones «Queen of Her other Realms and Territories» $\mathrm{y}$ «Head of the Commonwealth». Y se considera también evidencia de que la única Corona Imperial había evolucionado hacia una multiplicidad de Coronas Nacionales, el hecho de que los Maoríes acudieran en 1984 a la Reina de Nueva Zelanda solicitando la aplicación del Acuerdo de Waitangi, que habían firmado en 1840 con la Reina Victoria ${ }^{57}$. Pero no existe propiamente un marco normativo que clarifique la posición de la Monarca.

Desde el punto de vista teórico-constitucional, a la falta de concreción normativa sobre los roles que hoy día desempeña la Reina se une, como inconveniente, que la doctrina de los diferentes países implicados parece haber eludido el tratamiento en profundidad tanto de los roles como de ese juego sutil que en los sistemas derivados de Westminster combina componentes eficientes y componentes dignifi$\operatorname{cad} \mathrm{s}^{58}$ — de algún modo simbólicas, nobles, solemnes ${ }^{59}$ — que fundamentalmente satisfacían el sentimiento popular. La evolución de la posición de la Reina debe rastrearse, más que en las normas o en la literatura jurídica, en la historia da las negociaciones que, a veces con su presencia otras en su ausencia, se produjeron en las Conferencias los Jefes de Gobierno de la Mancomunidad ${ }^{60} \mathrm{y}$, junto a ello, en la importante contribución de la prensa escrita. Gracias a ello llegó a ser tan evidente la separación entre su cargo en la Commonwealth y el que ostenta en los dieciséis Reinos que algunos constitucionalistas, como Bogdanor ${ }^{61}$, han llegado a cuestionar hasta qué punto el monarca que la suceda realmente llegará a ocupar la Jefatura de

55 Detalladamente, Rush, Bonds of Empire: West Indians and Britishness from Victoria to Decolonization, Oxford University Press, 2011, 213-214, 217.

56 Bogdanor, The Monarchy, cit, 1995, pp. 240-247 p. 267. Discrepa CANDo SOMOANo, «La posición de la Corona en el modelo jurídico anglosajón», cit., 2000, vid. pp. 128-130, en especial nota al pie 74.

57 Cox, A Constitutional History of the New Zealand Monarchy, VDM, Saarbrücken, 2008, y DEL MISMO, «'The Crown Down Under': Issues and Trends in Australia and New Zealand», Smith/ Jackson (eds.), The Evolving Canadian Crown, McGill - Queen's Policy Studies Press, 2012, pp. 199ss.

58 Bagehot, The English Constitution, 1847; BoyCe, The Queen's Other Realms, 2008, pV; Petrie, La Monarquía en el siglo XX, Rialp, Madrid, 1956, pp. 58-64.

59 Véase Varela Suanzes-Carpegna, en su Estudio Preliminar a la publicación en español de la obra de Bagehot, La Constitución Inglesa, CEPC, 2010, p.XXX.

60 Craggs/ Kumarasingham, «Losing an Empire and Building a Role: The Queen, Geopolitics and the Construction of the Commonwealth Headship at the Lusaka Commonwealth Heads of Government Meeting, 1979», The Journal of Imperial and Commonwealth History, vol. 43 (1), 2015, pp. 80-98, 80.

61 Bogdanor, The Monarchy and the Constitution,1995,p. 263, 273. 
la Mancomunidad. Aunque resulte difícil de imaginar, nada impide que los miembros de la Commonwealth elijan otro líder o que, por ejemplo, se termine optando por una rotación en el cargo. En tiempos de Jorge VI no se había previsto aún que la Jefatura de la Mancomunidad fuera hereditaria ${ }^{62}$, pero su repentina muerte apenas 3 años después de la Declaración de Londres-, propició que Isabel II se convirtiera por herencia en Reina de los Realms de la Commonwealth y en Jefa de la Mancomunidad de Naciones. La longevidad de Isabel de Windsor ha hecho que, por el momento, parezca difícil entender la moderna Commonwealth disociada de ella ${ }^{63}$. Los acontecimientos que presenció - $-\mathrm{y}$, en algunos casos, presidió ${ }^{64}$ — la vinculan estrechamente con el tránsito del Imperio a la Mancomunidad y su posición se vio reforzada por acontecimientos como el vivido en la Conferencia de Lusaka (Zambia, 1979) en los que estratégicamente supo mostrar que su rol respecto del conjunto de la Commonwealth estaba separado del gobierno británico. Por mucho que Margaret Thatcher dijera lo contrario, dando a entender que la Reina lloraba con amargura la pérdida de sus antiguos territorios ${ }^{65}$, lo cierto es que Isabel de Windsor siempre expresó su entusiasmo por esta transformación, sabiendo conjugar las expectativas de la antigua Commonwealth (que demandaba su presencia), con la delicadeza de no levantar suspicacias en los nacionalismos de los nuevos miembros ${ }^{66}$. Y aquel viaje a Lusaka, en un momento de importantes tensiones en África, fue visto por la presa británica y de otros Estados como una actuación que cimentaba su rol oficial en la Mancomunidad de Naciones ${ }^{67}$ y evidenciaba la separación entre ese rol, de Jefa de la Mancomunidad, y el que desempeña en el Reino Unido y los demás Realms ${ }^{68}$.

\section{La coordinación de los procesos de reforma}

El concepto de Corona había resultado muy útil en la gobernanza de la colonias, habilitando al Reino Unido a actuar legislativa y ejecutivamente sobre los

62 Murphy/ Coope, Queen Elizabeth should be the final head of the Commonwealth, 2012, accesible en: http://www. commonwealthadvisorybureau.org.

63 Craggs/ Kumarasingham, «Losing an Empire», cit., 2015, p. 83-85, advierten que ninguna jefatura de una organización internacional ha mantenido a su líder durante más de seis décadas y que resultaría muy difícil a la Mancomunidad ofrecer un rival frente a su experiencia.

64 Detalladamente, varios autores, Freedoms at Midnight, número especial, Round Table: Commonwealth Journal of International Affairs, 97, $\mathrm{n}^{\circ}$ 398, 2008, pp. 637-807.

65 Howe, «Decolonisation and Imperial Aftershocks: The Thatcher Years», Jackson/ SAunders, Making Thatcher's Britain, Cambridge University Press, 2012, pp. 234-252.

66 Algunos autores consideran, incluso, que llegó a estimular la creación de algunas de las repúblicas, sobre todo en África. En este sentido, véase Murphy, Monarchy and the End of Empire, cit., 2015, pxi-xii, 13-14; Craggs/ Kumarasingham, «Losing an Empire», cit., 2015, p. 81; Pimplott, The Queen: Elizabeth II and the Monarchy, Harper Colllins, 2001, p. 465.

67 Pimplotт, The Queen: Elizabeth II and the Monarchy, Harper Colllins, 2001, p. 465.

68 Corby, «Queen and Commonwealth: an Unbreakable Bond», en Bennet/ Sriskanarajah, The Commonwealth at 60s: Past, Present and Future, The Royal Commonwealth Society, 2009, p. 43. 
territorios conquistados. Pero había instaurado una serie de principios jurídicos y prácticos que ejercerán una importante influencia, directa e indirecta, en los procesos constitucionales que llevaron a la independencia de éstos ${ }^{69}$. Ello se aprecia especialmente en el caso de las que se conoce como Constituciones de Whitehall. Los letrados de Whitehall redactaron al menos 33 proyectos constitucionales completos y algunas constituciones de independencia ${ }^{70}$, algo paradójico viniendo de un Estado que carece de Constitución escrita. En muchos casos, tales Constituciones no supusieron una automática transformación de las colonias en Estados independientes, sino que fueron el punto de partida de procesos de autogobierno que culminarían en éstos. Se considera que las constituciones creadas acertaron en dar respuesta a las necesidades de los Países del Caribe y las Islas del Pacífico, pero no fue este el caso de los países de Asia y especialmente a los de África, cuyos vínculos con el Reino Unido eran relativamente más recientes que los de países como India ${ }^{71}$.

Llegamos así al año 2011. Tras estar en vigor en un amplio Imperio, las normas que regían la sucesión al trono habían sido acogidas como propias en quince nuevos Reinos, y pasado a ser legislación doméstica en ellos ${ }^{72}$. Las implicaciones de esta incorporación normativa, sin embargo, no había tenido ocasión de ser vistas en la práctica, con excepciones puntuales como la del caso Donabue v. Canadá (2003). Impulsar un proceso de reforma ágil y coordinado, y que no propiciase disputas futuras sobre quién ocupa qué lugar en la línea sucesión ${ }^{73}$ requería despejar varias dudas. En primer lugar, debía establecerse si, como consecuencia del Estatuto de Westminster de 1931, todos los miembros de la Commonwealth debían participar en la reforma, o si esta cuestión sólo afectaba a los Realms. En la Conferencia Perth (2011) se entendió que, a pesar de que los países en los que no reinaba Isabel de Windsor estaban también unidos a la Commonwealth por su lealtad común a la Corona, la aplicabilidad del Estatuto debería quedar circunscrita a los dieciséis Reinos de la Commonwealt ${ }^{74}$.

La segunda de las dudas hacía referencia a si el Reino Unido y cada uno de los Realms tenían o no libertad para reformar, por separado, sus respectivas Coronas, o si, por el contrario, existía entre ellas un vínculo heredado de la situación imperial. Esto último implicaría que el Reino Unido no podría reformar su Corona sin el permiso

69 Twomey, The Chameleon Crown: The Queen and Her Australian Governors, Federation Press, 2006, caps. 1, 5; SAunders, «The Concept of the Crown», cit., 2015, pp. 882-884.

70 DALE, «The Making and Remaking of Commonwealth Constitutions», International Comparative Law Quarterly, vol. 42, 1993, pp. 67 y ss.

71 DALE, «The Making and Remaking», cit, 1993, pp. 80-81.

72 Véanse las declaraciones del entonces Ministro para la Reforma Política Mark HARper en la documentación que recoge los debates parlamentarios del Reino Unido, UK Hansard, Cámara de los Comunes, vol. 512, col. 1112, de 1 de julio de 2010. Más referencias en Twomey, A., «El cambio», cit., TRC, 2013, p. 138.

73 Bogdanor, The Monarchy and the Constitution, cit., 1995, p. 42; Gómez SÁnCHEZ, «La sucesión a la Corona», Rollnert-Liern (DIR.), Las monarquías Europeas en el sigo XXI, Ed. Sanz y Torres, 2007, pp. 147-177.

74 Vid. el listado que se ha proporcionado al inicio de este trabajo. TwOMEY, «El cambio», cit., TRC 2013, pp. 148-150 
del resto de los Realms, y, al mismo tiempo, que los Realms tenían una corona derivada de la del Reino Unido. Hazell/ Morris, por ejemplo, consideran — y critican— que conforme al Estatuto de Westminster el Reino Unido no pueda reformar su constitución sin el permiso del resto de Reinos (invirtiéndose aquí la situación constitucional que existía en tiempos del imperialismo). Pero Boyce, en cambio, entiende que el Reino Unido sí tiene libertad y que el asentimiento de los demás Realms obedece a que sus Coronas son derivadas de la británica, aunque no subordinadas ${ }^{75}$. Pero, como veremos, la cuestión de si las Coronas son o no derivadas y lo que ello implica, tampoco recibe una respuesta unívoca en el resto de los Realms.

También se plantearán, en tercer lugar, dudas respecto al rango que dentro de los respectivos ordenamientos jurídicos tenían las normas de sucesión al trono acogidas del ordenamiento británico. Se debatió especialmente si se trataba de normas que pertenecían al marco constitucional y, en coherencia, requerían de procesos de reforma con mayorías cualificadas o incluso de referendos, según el caso. Por las particulares características de sus ordenamientos jurídicos, en el Reino Unido y en Nueva Zelanda no será, como veremos, necesario determinar si las normas de sucesión al trono pertenecen o no al marco constitucional, porque el Parlamento de dichos países tiene potestad para modificar mediante legislación ordinaria cualquier previsión constitucional. Más complejo será, sin embargo, en casos como los de Australia, por el particular modo en que sus Estados Federados participaron en el proceso, o Canadá. En este último país, y a pesar de lo previsto en la Constitución, se eludió la participación de las Provincias en la reforma de las normas de sucesión al trono y ello motivó un recurso de inconstitucionalidad que, en segunda instancia, está aún pendiente de resolver. Por último, otras dudas, de menor calado, nacían de la estructura del Estatuto de Westminster, que combinaba un preámbulo y varias secciones, y de su ambiguo contenido material ${ }^{76}$. Así, por ejemplo, no llegaba a precisarse el modo en que debía ser obtenido el consentimiento de los Dominios a la reforma de las normas de sucesión. A ello han de añadirse que algunas secciones del estatuto, entre ellas la $4^{\mathrm{a}}$, se excluyeron en su día de aplicación en los Dominios de Canadá, Australia y Nueva Zelanda ${ }^{77}$.

\section{EL PROCESO DE REFORMA EN EL REINO UNIDO Y EL CONTENIDO DE LA LEY APROBADA POR EL PARLAMENTO}

De conformidad con lo expresado en el Acuerdo de Perth, el 5 de febrero de 2013 aprobaba la Cámara de los Comunes el proyecto de Ley de reforma de la Sucesión a la

75 Hazell/ Morris, «If the Queen Has No Reserve Powers Left,?», cit., 2015 pp. 5-32; Boyce, The Queen's Other Realms, cit., 2008, p. 23.

76 Detalladamente TwOMEY, «El cambio», cit., TRC 2013, pp. 148-150.

77 Wheare, The Statute of Westminster and Dominion Status, $5^{\mathrm{a}}$ ed., 1953, Oxford University Press, pp.278-280, 283. 
Corona, dándole tramite a la Cámara de los Lores. Junto a las previsiones en relación con la sucesión al trono y al matrimonio de los herederos con personas de fe católica, el proyecto contenía una reforma que derogaba la Royal Marriages Act de 1772, según la cuál todos los descendientes al trono necesitaban autorización del Soberano o Soberana para contraer matrimonio. A futuro se preveía limitar esta necesidad de autorización a las seis primeras personas en la línea de sucesión. Por otra parte se eliminaron: la prevalencia del varón sobre la mujer, aplicando de forma absoluta el principio de primogenitura respecto de los nacidos con posterioridad a la fecha del Acuerdo de Perth (octubre de 2011) , $^{78}$ y la prohibición de matrimonio con los católicos. No hubo cambios, como se ha explicado ya, en lo que se refiere a la exigencia de que el soberano deba estar en comunión con la Iglesia anglicana, evitando también abrir el debate sobre su función como cabeza de dicha Iglesia ${ }^{79}$.

Dado que la sucesión al trono es una cuestión excluida de la devolution, el Parlamento de Westminster no necesitó del consentimiento del Parlamento escocés, la Asamblea de Gales o la del Norte de Irlanda ${ }^{80}$. Por ello, la mayor atención del Parlamento Británico se centró en la coordinación entre su reforma y las de los demás Reinos firmantes del Acuerdo de Perth. Entre los documentos más interesantes de todo este proceso destacan los del Comité para la Reforma Política y Constitucional de la Casa de los Comunes. En diciembre de 2011, por ejemplo, publicó un informe ${ }^{81}$ con una lista preliminar de los estatutos que precisaban ser reformados para dar cumplimiento al Acuerdo de Perth. La lista comprendía: la Ley sobre el Juramento de la Coronación (Coronation Oath Act, 1688), el Bill of Rights (1689), el Acta de Establecimiento de 1701, la Ley de Unión con Escocia de 1707 (Union with Scotland Act), la Ley de Precedencia de la Princesa Sofía de 1711 (Princess Sophia's Precedence Act), la Ley de Matrimonios Reales (Royal Marriages $A c t$ ) de 1772, la Ley de Unión con Irlanda de 1800 (Union with Ireland Act), la Ley de Declaración de Accesión (Accession Declaration Act) de 1910, el Estatuto de Westminster de 1931 y la Ley de Regencia de 1937.

Como único acontecimiento llamativo en el proceso de tramitación, cabe reseñar que el Comité constitucional de la Casa de los Lores se opuso a una tramitación de urgencia (fast-track) ${ }^{82}$, razón por la cual la aprobación en la segunda cámara se demoró un poco más de lo previsto. Dicho Comité entendió que pese al anuncio

78 Prime Minister's Office, 'Afternoon press briefing for 12 October 2011', accesible en www. number10.gov.uk.

79 Vid. Parliament of The United KIngdom, Succession to the Crown Bill: Explanatory notes, Queen's Printer, 2012, y las críticas de algunos sectores doctrinales BonNEY/ Morris, Tuvalu and You, pp. 368s; MORRIS, «Half-opening cans of worms: the present state of «high» anglican establishment», Law and Justice Christian Law Review, 172, 2014, pp. 10ss.

80 Hunter, «A more modern Crown», cit., 201 2, p. 443.

81 House of Commons, Eleventh Report of Session 2010-2, HC 1615, 7 de diciembre de 2011, pp. 5-8. Disponible en www.publications.parliament.uk.

82 Lords Select Committee, Committee warns against rush to legislate on Succession to the Crown Will, Queen's Printer, 21 de enero de 2013. 
del primer embarazo de la Duquesa de Cambridge y la necesidad de cumplir con lo comprometido con el resto de los Reinos, la tramitación ordinaria permitía dar una solución adecuada y en plazo a la implementación del Acuerdo de Perth. No en vano, sólo se plantearía una situación de urgencia en el caso de que, habiendo nacido una primogénita — cosa que aun no había sucedido — estuviese en curso un segundo embarazo que, de llegar a término y dar lugar al nacimiento de un varón, pudiera dar lugar a la aplicación de la preferencia del varón en el mismo grado y línea. La ley recibió el refrendo real en abril de 2013 y fue publicada entonces, pero se anunció que, tal y como se había comprometido con el resto de los Realms, no entraría en vigor hasta que los demás terminasen sus procesos internos ${ }^{83}$.

\section{EL PROCESO DE REFORMA EN LOS REINOS DE LA COMMONWEALTH DE OCEANÍA}

\section{La reforma en Australia, con atención a las particularidades del proceso en Queensland}

El 1 de enero de 1901 se señala como fecha de origen de la monarquía de Australia, cuya corona ocupa en la actualidad y desde el 6 de febrero de 1952, Isabel, Reina de Australia por la Gracia de Dios ${ }^{84}$. La Reina es miembro formal de todos los parlamentos australianos —el federal y los de los seis estados federados- $\mathrm{y}$ todos los miembros del Parlamento federal juran su cargo en lealtad a la Reina Isabel; como apunta Patmore multitud de instituciones y sociedades son nombradas en su honor y, aunque en algunos ámbitos se esté renunciando a los orígenes monárquicos, aún hoy día los vestigios de la monarquía impregnan los espacios culturales de Australia ${ }^{85}$. La doctrina entiende que el hecho de que la Constitución australiana se desarrollase inicialmente como un estatuto colonial propició que no estuviese del todo claro si el procedimiento de reforma de la Corona (o eventualmente de su supresión) requería aplicar la sección $128^{a}$ de la Constitución — con implicación de todos los Estados-, o si, por el contrario, era posible realizar la reforma a través de Parlamento federal —en aplicación de la sección $51^{a}{ }^{86}$. Tampoco las constituciones de los estados de Australia habían recogido referencias sobre el modo en que habría de establecerse quién ha de

83 Sección 5 ${ }^{\text {a }}$, apartado 2 de la norma, y en el par. 42 del documento Succession to the Crown Bill, Explanatory Notes.

84 Galligan, «Australia», Butler/ Low (eds.), Sovereigns and Surrogates. Constitutional Heads of State in the Commonwealth, MacMillan, London, $1^{\circ}$ ed., 1991,p. 63.

85 Patmore, «The Head of State Debate: A Response to Sir David Smith and Professor David Flint», Australian Journal of Politics and History - AJPH, 2012, pp. 251-252.

86 Winterton, «An Australian Republic», Melbourne University Law Review, 16 (1988), pp. 467, 475. Estep, «Losing Jewels from the Crown: Considering the Future of the Monarchy in Australia and Canadá», Temple International and Comparative Law Journal, vol. 7, 1993, pp. 227-228. 
reinar $^{87}$. Una particularidad de la Corona en Mancomunidad de Australia es que, dentro de ella, se ha tendido a ver que las seis antiguas colonias australianas hoy Estados federados a esa Mancomunidad - de algún modo mantuvieron hasta 1986 una cierta relación semi-subordinada respecto del Reino Unido ${ }^{88}$. De ese origen parece que afloraron seis monarquías cuasi-soberanas, con un Gobernador General estatal (a diferencia del teniente gobernador de las provincias canadienses) y ello llevó a la doctrina discutir, incluso, si existen en Australia seis coronas separadas — es decir, si la Reina puede ser proclamada de forma separada por cada uno de los Estados australianos- o si, por el contrario, sólo existe un soberano por nación ${ }^{89}$. De ahí la trascendencia de decidir si, aún en el caso de que el Parlamento federal asumiera la tarea de la reforma en 2011, sería o no necesario solicitar consentimiento a los Estados federados ${ }^{90}$.

Una vez adoptado el Acuerdo de Perth y con el objetivo de precisar su proceso de implementación en Australia ${ }^{91}$, los primeros ministros de los Estados australianos se reunieron a mediados de diciembre de 2012 con Julia Gillard, entonces primera ministra de Australia, en el Consejo de Gobiernos Australianos (Council of Australian Governments). La primera ministra de Australia y cinco de los seis Estados mostraron su conformidad a que el proceso consistiese en aprobar una ley parlamentaria mediante la cual le fuera reconocida al Parlamento federal la competencia para consentir a la reforma propuesta por el Reino Unido en relación con la línea de sucesión al trono. El primer ministro de Queensland, sin embargo, sostuvo que cada uno de los seis Estados australianos debería aprobar sus propias normas de reforma de la sucesión al trono ${ }^{92} \mathrm{y}$, en coherencia, presentó en su Parlamento una propuesta en dicho sentido ${ }^{93}$. Como resultado, Queensland aprobó su propia Ley y poco después se aprobó la Ley australiana de reforma de la Sucesión a la Corona — Succession to the Crown Act- $\left(\mathrm{n}^{\circ} 23 / 2015\right)$. Esta última fue promulgada siguiendo la sección 51 (xxxvii) de la Constitución australiana y entró en vigor el 26 de marzo ${ }^{94}$ tras

87 Mason, «Constitutional Issues relationg to the Republic as they Affect the States», UNSW 21(3), 1998, pp. 750, 756; CARney, The Constitutional Systems of the Australian States and Territories, Cambridge University Press, 2006, pp. 318-338; Twomey, «One In, All In - Simultaneous Implementation of a Republic at Commonwealth State Levels», Murray, (ed.), Constitutional Perspectives on an Australian Republic: Essays in Honour of Professor George Winterton, Federation Press, Sidney, 2000, pp. 20-255

88 Boyce, The Queen's Other Realms, cit., 2008, pp. 92-94, y 145ss.

89 Winterton, «The Constitutional Position of Australian State Governors», LeE/ WinterTON (eds); Australian Constitutional Perspectives, Law Book, Sydney, 1992; Twomey, The Chameleon Crown: The Queen and her Australian Governors, Federation Press, Sydney, 2006, cap, 20; BoyCE, The Queen's Other Realms, cit., 2008, pp. 153-154.

90 Hoвbs, «Putting the 'Queen' back into Queensland», Alternative Law Journal 9, 2014, 39:1; TwoMEY, «El cambio», cit., TRC 2013, p. 166.

91 Morris, «The Succesion to the Crown Act 2013 has landed», The Constitutional Unit, Reino Unido, abril de 2015, p. 4; KIRBY, «The Queen and her Dominion Governors-Tittles, Honorifics and the Royal Succession in Post Imperial Australia», Australian Law Journal, 2016, 28-30.

92 Sobre este fenómeno, detalladamente HoBbs, «Putting the 'Queen'», 2014, 39:1.

93 Disponible en la página web del Parlamento de Queensland (www.parliament.qld.gov.au).

94 Succesion to the Crown Commencement Proclamation, www. comlaw, gov. au. 
obtener, en un proceso más largo de lo esperado, los estatutos promulgados entre 2013 y 2015 en los 6 Estados de la federación ${ }^{95}$ : Nueva Gales del Sur, Victoria, Queensland, Australia del Sur, Australia Occidental y Tasmania. Aprobada esta norma, y tras una nueva reunión del Consejo de Gobiernos, Queensland procedió a readaptar su recién aprobada normativa para que no se produjera un conflicto entre su legislación estatal y la federal.

Como apunte final respecto de Australia es oportuno hacer una breve referencia a la cuestión republicana. La constancia de aspiraciones republicanas se ha rastreado en Australia hasta al menos $1778^{96}$, aunque no sería hasta los años 90 cuando se produjeron los primeros debates importantes ${ }^{97}$. Como consecuencia de ellos en el año 1999 se tramitó en Australia una propuesta de reforma constitucional de transición de la federación hacia una república ${ }^{98}$. Esta propuesta obtuvo la mayoría absoluta necesaria en ambas cámaras parlamentarias, pero en el trámite referendario no recibió el respaldo popular mayoritario en ninguno de los seis Estados de la federación. Aunque la doctrina considera probable que a futuro se reabra esta cuestión ${ }^{99}$, la mayor dificultad para el avance estriba en la falta de acuerdo sobre el tipo de Jefatura de Estado que habría de suceder a la Corona. También se ha debatido si la monarquía debe o no continuar en los niveles estatales. Una proclamación de la republica a nivel federal haría innecesarias las oficinas de los gobernadores estatales, pero los expertos apuntan que en tal supuesto es previsible que los Estados no quisieran perder el poder formal que descansa sobre ellas ${ }^{100}$. De hecho, consta que en algunos Estados —entre ellos, como se ha dicho, Queensland— se está reforzando el uso de símbolos que hacen referencia a la Corona.

\section{La reforma de la Sucesión al Trono en Nueva Zelanda}

La Corona británica reclamó la soberanía sobre Nueva Zelanda en 1840 y el Dominio accedió al autogobierno el 26 de septiembre de 1907. Al igual que en

95 Nueva Gales del Sur: Succesion to the Crown Act (request), aprobada el 25 de junio de 2013; Queensland: Succession to the Crown Act de 2 de mayo de 2013, reformando la sucesión y solicitando al parlamento de Australia que haga lo propio; Australia del Sur: Request aprobado el 17 de junio de 2014; Tasmania, Request aprobado el 29 de agosto de 2013; Victoria; Request aprobado el 17 de octubre de 2013 y Australia del Oeste: Request aprobado el 24 de febrero de 2015.

96 Mackeena, A Captive Republic, Cambridge, 1996, p. 10.

97 Vid. Estep, «Losing Jewels», cit., 1993, p. 218; Patmore, «The Head of State Debate: A Response», cit., 2012, pp. 251-252.

98 Constitution Alteration (Establishment of Republic) Bill 1999. Vid. HunTER, «A more modern Crown», cit., 20I2, cit., p. 450; MANSILlO, «Loyal to the Crown: shifting public opinion towards the monarchy in Australia", Australian Journal of Political Science, 2016, 51:2, pp. 213-235.

99 Vid. Murray, Constitutional Perspectives on an Australian Republic: Essays in Honour of Pofessor George Winterton, Sidney, 2010 y Williams/ Hume, People Power: the History and Future of the Referendum in Anstralia, Sidney, 2010.

100 Boyce, The Queen's Other Realms, cit., 2008, p. 168-169. 
Canadá y Australia, la Reina actual, Isabel de Windsor, accedió al trono Neozelandés al fallecer su padre, el Rey Jorge VI, el 6 de febrero de 1952. La mayor parte las tareas de la Corona Neozelandesa, a la que Boyce se refiere como Kiwi Crown, son asumidas por el Gobernador General. La Constitución Neozelandesa de 1986 establece que ningún británico ni miembro del gobierno de otro Reino de la Mancomunidad de Naciones puede asesorar a la soberana en ninguna cuestión que se refiera al estado de Nueva Zelanda, pudiendo sólo ser asesorada por los Ministros de la Corona de Nueva Zelanda.

La experiencia monárquica neozelandesa ha compartido con Australia y Canadá muchos de los hitos constitucionales y políticos de su evolución con excepción, claro está, de las complicaciones que se han derivado las estructuras federales de estos últimos ${ }^{101}$. Es más, el experto constitucionalista Noel Cox, presidente además de la Liga Monárquica de Nueva Zelanda, escribía en 2010 que Canadá, Australia y Nueva no sólo comparten la misma Reina. En ellos son también comunes sus orígenes constitucionales y los principios subyacentes, y común es también la percepción de lo que implica ser una monarquía constitucional. En buena medida, se trata de principios mayoritariamente inherentes al modelo británico de gobierno ${ }^{102}$ que fueron acogidos en los nuevos marcos constitucionales. No obstante, es evidente que existen marcadas diferencias entre cada uno de estos sistemas de gobierno. Por ejemplo, y a diferencia por ejemplo de lo que sucede con la de Canadá, la Constitución de Nueva Zelanda de no se funda en un único estatuto y el Parlamento no tiene límites formales para legislar, tal y como sucede en el Reino Unido de la Gran Bretaña y Norte de Irlanda; el Parlamento puede reformar normas constitucionales a través de un procedimiento legislativo ordinario ${ }^{103}$.

Las normas de sucesión al Trono en Nueva Zelanda están establecidas en la legislación nacional, en las que se indica que, fallecido el soberano, todas sus funciones, obligaciones, poderes, autoridades, derechos, privilegios y dignidades de la Corona se transmitirán a su sucesor «de acuerdo con el Acta de Establecimiento promulgado por el Reino Unido y cualquier otra norma relativa a la sucesión al Trono» ${ }^{104}$. El problema estriba en que desde el 1 de enero de 1987 se estableció que la legislación británica no tendría ya efectos directos en Nueva Zelanda y ello incluiría, claro está, cualquier norma británica aprobada para reformar la sucesión al trono. Además del consentimiento del Estado Neozelandés, la doctrina entendía en el plano teórico que una eventual reforma de la sucesión al trono que pretendiese tener efectos en Nueva Zelanda requeriría el consentimiento de dos estados libres

101 Boyce, The Queen's Other Realms, cit., 2008, pp.170-171.

102 Cox, «'The Crown Down Under': Issues and Trends», cit., 2012, pp. 199ss.

103 Joseph, Constitutional and Administrative Law in New Zealand, Ed. Brookes, Wellington, $2^{\mathrm{a}}$ ed., 2001, pp. 112-116.

104 Sección $5^{\text {a }}$ de la Constitution Act de 1986, Nueva Zelanda. Con más referencias HunTer, «A more modern Crown», cit., 2012 , cit., p. 455. 
asociados a Nueva Zelanda: las Islas Cook y Niue ${ }^{105}$, que en su día no optaron por una independencia plena ${ }^{106}$ y en cuyas constituciones prevén que la autoridad ejecutiva es investida en su majestad la Reina de Nueva Zelanda.

Llegado el momento de implementar el Acuerdo de Perth Nueva Zelanda optó por un proceso muy sencillo, que se transitó con rapidez y sin incidentes. El gobierno neozelandés, presidido por Judith Collins, presentó la reforma ante el Parlamento de Nueva Zelanda el 18 de febrero de 2013 y, tras el trámite parlamentario, el texto final se promulgó en diciembre de $2013^{107}$. Dicha norma derogó de Nueva Zelanda la Ley de Matrimonios reales de 1772, y reformó parcialmente la Carta de Derechos (Bill of Rights) de 1689 y el Acta de Establecimiento de 1701.

Como apunte final cabe indicar que, en términos comparativos, en Nueva Zelanda la tradición republicana no ha sido tan significativa como en Australia. En cualquier caso, el ministro Bolger propuso en 1994 que entrado el nuevo siglo Nueva Zelanda habría de transformarse en una república. En su opinión, ello era necesario para completar la identidad nacional del país, atender al multiculturalismo y dar por enterrada la herencia colonial, al tiempo que permitiría que, como país del Pacífico Sur, Nueva Zelanda abriese relaciones comerciales con Asia. El propio Bolger reconocía haber hablado en varias ocasiones sobre ello con la Reina Isabel $\mathrm{II}^{108}$, y si bien era consciente del escaso respaldo popular que tenía su propuesta, no supo prever que de su propio partido podría nacer una oposición que terminaría debilitando a su gobierno ${ }^{109}$. El sentimiento de vinculación con la Gran Bretaña demostró ser — al menos entonces - más consistente y reacio al cuestionamiento que en Australia y Canadá. De hecho, a corto y medio plazo los expertos no creen que en Nueva Zelanda vaya a prosperar una propuesta republicana, aun incluso en el caso de que otros países como Australia llegasen a aprobarla ${ }^{110}$.

\section{La reforma en los Otros Reinos del Pacífico: las Islas Salomón, Papúa Nueva Guinea y Tuvalú}

De las naciones insulares del Pacifico Suroeste que están vinculadas a la Mancomunidad Británica de Naciones, cinco son monarquías en las que Isabel de

105 Twomey, «Changing the Rules of Succession to the Throne», Sydney Law School Research Paper, $\mathrm{n}^{\circ}$ $11 / 71,2011$, pp. 19-20.

106 GHai/ CotTrel, «South West Pacific», Butler/ Low (eds.), Sovereigns and Surrogates, cit., 1991, p. 235 .

107 Royal Succesion Bill, Queens Printer, Wellington, 2013, pp. 10-12.

108 Como explica el propio Bolger en sus memorias, vid. Bolger, Bolger: A view from the top - my seven years as Prime Minister, Viking, 1998.

109 Cox, «The Crown Down Under': Issues and Trends», cit., 2012, pp. 199ss.

110 Boyce, The Queen's, cit., 2008, pp. 170-171, y pp. 209 y ss. 
Windsor es la Jefa del Estado: de una parte, las Islas Cook y Niue, que como se ha dicho son estados libres asociados a Nueva Zelanda en los que un Gobernador-general representa a la Reina de Nueva Zelanda; y, de otra, Papúa Nueva Guinea, Islas Salomón y Tuvalú ${ }^{111}$. Estos tres últimos países se independizaron a finales de los 70 y principios de los años $80^{112}$ y acogieron como Jefa de Estado a Isabel de Windsor. Ha de destacarse que, a diferencia de otros Reinos, Papúa Nueva Guinea no se independizó del Reino Unido, sino de Australia. La Papua New Guinea Independence Act (1975) dio por finalizada toda soberanía, derechos de soberanía o derechos de administración de Australia sobre su territorio, y rechazó la aplicación a futuro de cualquier norma australiana o imperial sobre el mismo. Y cuando el 15 de agosto de 1975 proclamó su Constitución, adoptó la forma de Monarquía Parlamentaria indicando que Isabel de Windsor había consentido en ser en Reina y Jefa de Estado de Papúa Nueva Guinea (secc. 82 de la Constitución). En el texto constitucional se recogía además, de forma expresa, que las previsiones relativas a la Reina se extendían a sus herederos y sucesores en la soberanía de la Gran Bretaña y el Norte de Irlanda. Dado, por tanto, que la Reina es monarca de Papúa por una provisión libremente aceptada por la soberanía popular, en principio se entiende que cualquier persona que le suceda en el trono del Reino Unido, independientemente de las normas de sucesión que en determinado momento haya establecido Westminster, será monarca en Papúa Nueva Guinea. No obstante, una mayoría cualificada del Parlamento podría modificar la Constitución, en el caso de que se decidiera incorporar a ésta algunas normas sobre la sucesión al trono.

Por su parte, las Islas Salomón obtuvieron su independencia el 7 de julio de 1978, nombrando como Jefa de Estado a Su Majestad - Isabel de Windsor-y extendiendo las previsiones legales relativas a ésta a los que, según la soberanía del Reino Unido, fueran sus herederos y sucesores. Esta previsión obedecía, según Ghai, a que en el momento de la elaboración de la constitución independiente se pensó que la experiencia de la Reina supondría una importante contribución al servicio del nuevo gobierno ${ }^{113}$. La ausencia de una previsión similar a la de la sección 83 de la Constitución de Nueva Guinea hace que la doctrina entienda que, como consecuencia de la independencia, las normas de sucesión al trono que estaban vigentes en el Reino Unido pasaron a ser acogidas en el ordenamiento de las Islas Salomón, pero que a futuro el Parlamento británico habría perdido su capacidad para legislar con efectos para las Islas Salomón. De ahí que en la década de los 90 y principios de 2000 se sostuviera

111 Isabel de Windsor fue también Reina de Fiji hasta 1987. Véase también supra, en nota 6.

112 GHai/ CotTrel, «South West Pacific», Butler/ Low (eds.), Sovereigns and Surrogates, cit., 1991, pp. 233-235.

113 GHaI, «The Making of the Independence Constitution», Larmour (ed.) Solomon Islands Politics, Institute of Pacific Studies - Universidad del Pacífico Sur, 1983, pp. 9-52; y GHAI/ CotTreL, «South West Pacific», cit., 1991, pp. 234-236. 
que en un eventual proceso de reforma británica de las normas de sucesión sería necesario clarificar en qué forma dar acogida a las nuevas previsiones legales en las Islas Salomón.

En el caso de Tuvalú, el Reino menos poblado de los que están asociados a la Commonwealth ${ }^{114}$, la independencia se obtuvo el 1 de octubre de 1978 (Tuvalu Act 1978) y en 1985 se proclamó una nueva Constitución (Tuvalu Constitution). En ella se indica que Isabel de Windsor — con el 90\% del apoyo parlamentario de Tuvalú115 — consintió ser la Soberana y su Jefa de Estado. Conforme a la sección 49 de la Constitución, las previsiones sobre el Monarca en la Constitución se extienden también a los herederos y a los sucesores de Isabel II conforme a la ley, precisando que en tanto no se promulgue una ley propia será de aplicación en Tuvalú la norma que esté en vigor en Inglaterra ${ }^{116}$. Se entendía también, en coherencia, que mientras no se crease una normativa propia en Tuvalú, cualquier cambio que se realizase en Westminster y afectase a la sucesión al trono sería también de aplicación inmediata en Tuvalú ${ }^{117}$.

Llegado el momento histórico de la implementación del Acuerdo de Perth, y a pesar de que en el caso de las Islas Salomón no estaba del todo claro, estos tres países decantaron por una misma opción. Así, y según el Informe presentado por Tankerness en la Cámara de los Lores ${ }^{118}$, en los tres casos se decidió que la implementación de la reforma acordada sobre la línea de sucesión al trono no requería ninguna modificación normativa, porque entienden que los herederos y sucesores al trono son, en cada uno de esos Reinos, los mismos que los previstos en Reino Unido respecto de su Corona.

Como se ha hecho respecto de otros Reinos, hemos investigado si en estos países han existido o existen propuestas de evolución hacia sistemas republicanos. Se han encontrado algunas referencias de planteamientos republicanos en Tuvalú y las Islas Salomón de los años 80, pero coincidimos con Ghai/ Cottrel en que no se han producido por el momento iniciativas sólidas en esta dirección ${ }^{119}$.

114 Bonney/ Morris, «Tuvalu and You», The Political Quarterly, vol. 83, n 2, 2012, pp. 368ss.

115 Ghai/ CotTrel, «South West Pacific», Butler/ Low (eds.), Sovereigns and Surrogates, cit., 1991, p. $265-266$.

116 Constitución de Tuvalú de 1978, Parte 4, sección 1, artículo 49, y artículo 13.2.

117 En el mismo sentido HunTer, «A more modern Crown», cit., 20 I 2,p. 463.

118 Tankerness, Parlamentary Debates, House of Lords, col. col, 310, 2013.

119 Ghai/ CotTrel, «South West Pacific», Butler/ Low (eds.), Sovereigns and Surrogates, cit., 1991, p. $265-266$. 


\section{EL PROCESO DE REFORMA EN LOS REINOS DE LA COMMONWEALTH DEL CONTINENTE AMERICANO}

\section{El proceso de reforma de la sucesión al trono en Canadá, con atención a los dos recursos de inconstitucionalidad planteados}

\subsection{Algunas notas sobre la llamada Corona de Arces}

El concepto de la Corona ha evolucionado desde que Canadá se estableció como Dominio bajo la Corona del Reino Unido en $1867^{120}$, aunque en lo esencial cabe decir que a día de hoy la Oficina de la Reina, el Gobernador General y los Tenientes Gobernadores provinciales (Leutenant Governors) mantienen un arraigo constitucional con muchos elementos de aquellos tiempos ${ }^{121}$. Asimismo, e igual que en otros países de la Mancomunidad Constitucional, esta Corona ha ido adoptando una figura singular, mediante convenciones constitucionales y usos, dando lugar a la que se describe como «Corona de Arces»(Crown of Maples) ${ }^{122}$. A partir del Informe Balfour (1926) y el Estatuto de Westminster, junto con la Royal Style and Tittles Act (1953) aprobada por el Parlamento Canadiense se produjo una evolución que culminó con la Canada Act de 1982, momento en el que se cristaliza totalmente la distinción entre la Corona del Reino Unido y la Corona de Canadá. La sección 41 de la Constitución recoge el estatuto constitucional y los poderes de la Oficina de la Reina en Canadá, similares en principio a los que ostenta respecto al Reino Unido, aunque con divergencias y limites derivados de la Constitución canadiense $-\mathrm{y}$ atendiendo también a su distribución federal-provincial de poderes.

La Corona resulta de utilidad al constitucional y monárquico Estado moderno de Canadá ${ }^{123}$ en un compendio de poderes formales, ejecutivos y administrativos. Con el tiempo, conforme a los Parlamentos provinciales se les fueron reconociendo poder legislativo ${ }^{124}$, comenzó a entenderse que los Tenientes Gobernadores eran representantes directos de la Corona en las respectivas provincias, a pesar de que eran propuestos (y podían ser cesados) por el Gobernador General. De ahí que se explique que la Reina ejerce distintas potestades respecto de la Federación y las provincias, y que actúa, según el caso, a través de sus representantes constitucionales,

120 El preámbulo de la British North America Act — también conocida como Constitution Act, 1867establece que las provincias de la federación están unidas en un Dominio bajo la Corona del Reino Unido y con una Constitución similar en los principios a la del Reino Unido.

121 Newman, «Some Observations on the Queen, the Crown, the Constitution and the Courts», Review of Constitutional Studies/ Revue d'etudes constitutionelles, vol. 22/1 (monografico The Crown in the 21st Century), 2017, p. 55.

122 Department of Canadian Heritage, A Crown of Maples. Constitutional Monarchy in Canadá, 2012.

123 Sмiтн, The Invisible Crown - The First Principle of Canadian Government, Toronto University Press, 1995 (reeditado en 2013), p. xiv.

124 SмITH, The Invisible Crown, cit, 1995, pXIV. 
que son el Gobernador General y los Tenientes Gobernadores. Todo ello no ha sido obstáculo para que en Canadá hayan existido propuestas de evolución hacia un sistema republicano. Incluso durante la implementación del Acuerdo de Perth en 2012 se presentaron propuestas en la convención federal del partido liberal. Pero lo cierto es que, desde tiempo atrás, el debate sobre la posición de la monarquía en Canadá se ha venido de alguna forma relegando como consecuencia de otras cuestiones domésticas. Entre ellas: el debate sobre el lugar de Quebec en el conjunto de Canadá; las presiones sociales a favor del avance hacia una nación multicultural tras los efectos de la inmigración- ${ }^{125}$; y la necesidad de defender su identidad frente a la cercana presencia de los Estados Unidos de América ${ }^{126}$.

\subsection{El debate sobre la participación (o no) de las Provincias Canadienses en el proceso de reforma de las normas de sucesión}

Ya antes del Acuerdo de Perth se habían publicado opiniones doctrinales sobre el procedimiento que debería, en su caso, seguirse para reformar cualquier aspecto de la Corona de Canadá, incluyendo las normas de sucesión. Se defendía que dichas reformas deberían seguir el tramite previsto en la sección 41 de la Constitución, toda vez que dicha sección acoge la posibilidad de enmiendas que afecten a la «Oficina de la Reina» ${ }^{127}$. La consecuencia práctica más notable de esta interpretación era la necesidad de obtener, en ese proceso, el consenso de las diez Provincias canadienses. Como era de esperar, este debate se reabrió en el proceso de implementación del Acuerdo de Perth en Canadá. Se discutió, en primer lugar, si el Parlamento Federal debía, sin más, prestar consentimiento o si, por el contrario, era necesario aprobar una ley sustantiva ${ }^{128}$, por el hecho de que la ausencia de normas sobre la sucesión implicaba una cierta «Des-Canadianización» de la Corona o des-patriación, o incluso de repliegue de las implicaciones de la independencia Canadiense como estado soberano. En segundo lugar, y en relación con las Provincias, se discutió si era o no necesario, y en su caso cómo, recabar de algún modo el consentimiento de las provincias canadienses, toda vez que sus poderes son mayores que los de los Estados de Australia ${ }^{129}$. Algunos expertos como Lagassé sostenían que cualquier

125 EsTEP, «Losing Jewels from the Crown», cit., 1993, pp. 236-240.

126 Detalladamente EsTEP, «Losing Jewels», cit.,p. 218-220.

127 HogG, Constitutional Law of Canada, cit., 1995, pp. 212-213; EsTEP, «Losing Jewels», cit., 1993, p. $229-231$.

128 Taillon/ Motard, Bedard/ Lagassé (eds), La Couronne et le Parlement/ The Crown in Parliament, Editions Yvon Blais, Montreal, 2015; Lagassé/ Bowden, «Royal Suceesion and the Canadian Crown as a Corporation Sole», 2014, Constitutional Forum 23, n 1, 2014, pp. 17-26; TofFoli/ BenOIT, «More is Needed to Change the Rules of Succesion for Canada», Canadian Parliamentary Review, 2013, vol. 36, pp. 10ss.

129 Smith/ Mann, A Tale of Two Dominions: Why the Procedures for Changing the Rules of Succession are Different in Canada and Australia», Commonwealth and Comparative Politics Journal, vol, 52, $\mathrm{n}^{\circ}$ 3, 2014, pp. 376-401, 376-377. 
cambio constitucional formal en relación con la oficina de la Reina implicaba no sólo la autorización de las cámaras federales sino de las asambleas legislativas de las diez provincias canadienses ${ }^{130}$. Otros entendían, en cambio, que no era necesario; que el planteamiento de Australia reflejaba la relación directa de los Gobernadores de los Estados federados de Australia con la Reina, a diferencia de lo que sucede en Canadá, donde los Tenientes Gobernadores son propuestos por el Gobernador General. También se expresaron voces que entendieron que la reforma no planteaba dudas de constitucionalidad ${ }^{131}$. Walters, por ejemplo, explicaba que la propia regla de la identificación de la Corona (o el principio de simetría), según la cual el Rey o Reina de Canadá es la misma persona que es Rey o Reina del Reino Unido conforme a las normas de sucesión allí vigentes ${ }^{132}$, hace innecesario promulgar una norma nacional sustantiva sobre la sucesión al trono.

Conviene detenerse un momento en la propuesta de Lagassé, en tanto su tesis ha servido de base a uno de los recursos de inconstitucionalidad abiertos contra la Ley de reforma de la Sucesión al Trono en Canadá. Lagassé y Baud recuerdan que las notas explicativas de la reforma del parágrafo 41 (a) de la Constitución Canadiense de 1982 señalaban que dicho parágrafo se explica por sí mismo, algo que parece haber dejado de ser así tras la aprobación de la Ley de Sucesión al Trono de $2013^{133}$. La clave pasaba por determinar si las normas de sucesión al trono forman parte del Derecho Canadiense y, en tal caso, si debe entenderse que los cambios afectan o no a la «Oficina de la Reina» ${ }^{134}$, algo que estaría claro en el caso de una reforma que afectase a las inmunidades y privilegios de la Corona o a las prerrogativas troncales que se ejercen por el Primer Ministro o el gabinete en nombre de ésta. Como argumento que complementa su tesis, estos autores destacan que en el año 2003, en el caso Donahue v. Canada, la Corte Superior de Justicia de Ontario sostuvo que el Acta de Establecimiento y otras normas de sucesión al trono formaban parte del derecho constitucional Canadiense por el principio de recepción normativa. Sobre esa base defendieron que reformar estas normas, con

130 Lagassè/ Baud, «The Crown and Constitutional Amendment in Canada», Bédard/Lagassé, cit., 2015, y en «The Crown and Constitutional Amendment after the Senate Reform and Supreme Court References», Macfarlane (ed.), Constitutional Amendment in Canada, Toronto University Press, 2016, pp. $105-125$.

131 Así, durante el estudio de la norma en el Comité del Senado, opinaron Pelletier, Heard y Walters; vid. también HogG, «Succession to the Throne», National Journal of Constitutional Law 33, 2014 , pp. 83-94; Hawkins, «The Monarch is Dead: 'Long Live the Monarch': Canada's Assent to amending the Rules of Succesion», Journal of Parlamentary and Political Law 7/3, 2013, p. 592; WALTERS, «Succesion to the Throne», BÉdARD/ LaGASsÉ, loc. cit.

132 CoRnell, «Succesion to the Throne and the Canadian Charter of Rights and Freedoms», Law and Business Review of the Americas, vol. 21 (2), 2015, p. 201; HoGG, «Succession to the Throne», cit., 2014, pp. 83, 89-90, 92-93.

133 Lagassé/ Baud, «The Crown and Constitutional Amendment in Canadá», cit., 2015, p. 203.

134 Lagassé/ Bowden, «Royal Succession and the Canadian Crown as Corporation Sole: A Critique of Canada's Succession to the Throne Act 2013», Constitutional Forum 23, p. 15; HogG, «Succession to the Throne», cit., 2014, p. 83. 
independencia de mostrar conformidad con las normas aprobadas en Reino Unido, requeriría una reforma de la normativa nacional aplicando la sección 41 (a) de la Constitución — con el concurso de ambas cámaras del Parlamento federal y de las asambleas provinciales-o, en su caso, la sección 44 - con la participación única del Parlamento Federal-.

Con el apoyo de otros expertos ${ }^{135}$, el gobierno canadiense entendió, sin embargo, que la implementación del Acuerdo de Perth implicaba una determinación de la identidad de la persona que ocupará el cargo de monarca en la Corona de Canadá y que Canadá podía consentir la aplicación de la Ley británica, identificando así su propio monarca. Walters sostiene que el modo en que la Reina del Reino Unido pasó a ser la Reina en cada uno de los reinos es una cuestión totalmente interna o doméstica de dicho país. En ese proceso, en su opinión, cada uno de los Reinos pudo optar entre un principio de identificación de la Corona ${ }^{136}$ — no siendo pues, necesaria, una legislación propia para la sucesión al trono- o, por el contrario, legislar específicamente la sucesión al trono ${ }^{137}$. Este principio no implica una conexión o unidad entre las Coronas como entidades, sino simplemente identifica a la persona que ocupa el cargo. Así, se procedió a aprobar en el Parlamento Federal la Ley de Sucesión al Trono de 2013, una Ley por la que Canadá consentía para sí los efectos de la modificación legal presentada a trámite como Succesion to the Crown Bill en el Parlamento británico y que se aprobaría como Succesion to the Crown Act. ${ }^{138}$. De hecho el título de la Ley es Succesion to the Throne Act. An Act to assent to alterations in the law touching the Succesion to the Throne, presentada en la cámara baja canadiense el 31 de enero de 2013 (como Bill C-53), aprobada el 4 de febrero, y aprobada por el Senado canadiense en marzo de $2013^{139}$. En su contenido consentía «la modificación en las normas relativas a la sucesión al trono establecidas en el proyecto presentado ante el Parlamento del Reino Unido que lleva por título «A Bill to Make succession to the Crown not dependent on Gender; to make provision about Royal Marriages; and for connected purposes».

Este procedimiento por el que el Parlamento federal asume la función legislativa parece similar al que empleó Australia, pero han de destacarse importantes diferencias. En la Constitución de Canadá no está previsto un poder de inter-delegación similar al de la Constitución de la Mancomunidad de Australia —razón

135 HogG, «Succession to the Throne», cit., 2014, p. 83; Hawkins, «The Monarch is Dead», cit., p. 593; Walters, «Submission to the Standing Senate Committee on Legal and Constitutional Affairs Concerning Bill C-53, An Act to assent to alterations in the Law touching the Succession to the Throne», de 5 de marzo de 2013. confusión.

136 Expresión que emplea HogG, «Succession to the Throne», cit., 2014, p. 90, pero puede generar

137 WaLters, «Sucession to the Throne», cit., 2015,p. 267.

138 CoRnell, «Succesion to the Throne», cit., 2015, pp. 201-202.

139 Senate of Canada, «LCJC Meeting No 74», de 20 de marzo de 2013, disponible en senparlvu. parl.gc.ca.. 
por la que no se pidió a las Provincias un permiso similar al que los Estados emitieron en Australia-. Lo que sí existe es un poder general y residual del Parlamento Canadiense que le permite promulgar leyes para la paz, el orden y el buen o gobierno de Canadá (Peace, Order and Good Government-POGG) que puede emplearse en las materias no asignadas en exclusiva a las provincias, o cuando estuviera justificado por interés nacional o razones de emergencia ${ }^{140}$. Según el ministro de Justicia canadiense, la tramitación de la reforma de la sucesión al Trono podía acogerse al POGG y se amparaba, además, en la práctica y la tradición de Canadá. En su opinión, esa había sido también la forma en la que se procedió en los tres precedentes de reformas relacionadas con la sucesión al trono que se aprobaron en el siglo XX: la primera, en tiempos de la abdicación de Eduardo VIII (1936-1937) ${ }^{141}$ y, posteriormente, en relación con las normas de estilo y los títulos reales (1947 y 1953) ${ }^{142}$. En los tres casos el Parlamento de Canadá expresó su consentimiento a la norma sustantiva aprobada en el parlamento británico ${ }^{143}$, aunque esta opinión parece obviar que dichos precedentes son anteriores a la entrada en vigor de la Constitución Canadiense de 1982.

\subsection{Los recursos de inconstitucionalidad contra la nueva Ley canadiense de Sucesión al Trono}

En la línea del recurso planteado por O'Donabue diez años antes, Bryan Teskey presentó un recurso ante la Corte Superior de Ontario sobre la posibilidad de que Canadá estableciera una línea propia de sucesión al trono, diferente a la del resto de los reinos de la Commonwealth ${ }^{144}$. El recurrente alegaba la inconstitucionalidad de la normativa, por contravención de la sección $2^{\mathrm{a}}$ de la Constitución de Canadá de 1982 y la sección 15 de la Carta Canadiense de Derechos y Libertades, toda vez que la Ley de reforma de la Sucesión no eliminaba la prohibición de que un católico accediese al trono de Canadá145. Como era de esperar, y con el precedente del caso O'Donabue, la Corte dictó sentencia en los mismos términos ${ }^{146}$.

140 Monahan/ Shaw, Constitutional Law, Irwin Law, Toronto, 2013, pp. 115-117 y Hogg, Constitutional Law of Canada, Carswell, Toronto, 2003, pp. 17-1-17-32.

141 En la abdicación de Eduardo VIII y posterior coronación de Jorge VI en 1937, mediante la Succesion to the Throne Act, SC 1937, que implicó el asentimiento de Canadá a la reforma realizada por el Parlamento británico como «His Majesty's Declaration of Abdication Act», de 1936.

142 Royal Tittle and Styles Act de 1927 y 1953.

143 Newman, «Some Observations», Review of Constitutional Studies 22 (1), 2017, p. 71.

144 Teskey versus Attorney General of Canada, Ontario Superior Court of Justice, 9 de agosto de 2013, disponible en Hackland R.S.J.

145 Lagassé/ Baud, «The Crown and Constitutional Amendment in Canadá», cit., 2015, p. 203.

146 Esto es, consideró que las normas de sucesión al trono no eran parte de la Constitución y que Teskey no estaba legitimado para actuar en dicha causa por no pertenecer a la línea de sucesión al trono. Sentencia Teskey v. Canada (Attorney General), 2013 ONSC 6386, para. 7, Canada Ontario Superior Court Journal. 
En la sentencia, cuyo ponente fue Rouleau ${ }^{147}$, se indicó que las normas que gobiernan la sucesión al trono compartido son parte de la Constitución no escrita y no expresada y que, por tal motivo, tienen inmunidad frente a recursos que cuestionen su contravención con la sección 15 de la Carta Canadiense de Derechos Fundamentales $^{148}$, algo que confirmó la Corte de Apelaciones de Ontario ${ }^{149}$.

El segundo de los recursos fue presentado por dos juristas de Laval, Geneviéve Motard y Patrick Taillon, ante la Corte Superior de Quebec. Entendiendo que la reforma realizada afectaba a la «Oficina de la Reina», los recurrentes consideraban que la reforma hubiera requerido la intervención no solo del Parlamento Federal sino también de los Parlamentos provinciales ${ }^{150}$. El gobierno de Quebec se sumó a este recurso ${ }^{151}$. Esta fue la primera ocasión en la que el art. 41 (a) de la Constitución canadiense fue objeto de interpretación judicial ${ }^{152}$, por lo que la sentencia tuvo que abordar, entre otras cosas, la cuestión de si las reformas previstas en la Ley de Sucesión al Trono afectaban o no a la parte V de la Constitución de 1982 y, en su caso, pronunciarse sobre el procedimiento que debería haberse seguido para dicha reforma. En su sentencia, el juez Claude Bouchard repasa la historia de las normas de sucesión desde el Bill of Rights, y analiza los argumentos que en un sentido y otro habían expuesto los partidos políticos y la doctrina. A la vista de dichos fundamentos, se concluye que en aplicación del principio de simetría constitucional el Rey o Reina de Canadá será quien ocupe el trono del Reino Unido. Dicho principio, en opinión del juez, no fue modificado por el Estatuto de Westminster de 1931 y, a diferencia de las normas que regulan la Oficina de la Reina en Canadá, las normas de sucesión tampoco habían pasado a forma parte de la Constitución canadiense, por lo que el Reino Unido conservaba la potestad de modificar las normas de sucesión. En coherencia, la reforma de las normas de sucesión no necesitaba del consenso de las Provincias canadienses ${ }^{153}$. Dicha sentencia, de febrero de 2016, fue recurrida ante la Corte de Apelaciones de Quebec ${ }^{154}$ y en febrero de 2018 se ha anunciado que la sentencia se espera, como pronto, para este verano. Ha de hacerse notar que, de ser considerada inconstitucional la norma y

147 Spector, «Why Canada must take on Britain over the 1701 Act of Settlement», The Globe and Mail, de 30 de agosto de 2007.

148 O'Donabue v. Her Majesty the Queen in Right of Canada and Her Majesty the Queen in Right of Contario (2003) OJ 2764, 17-39 (SCJ). Vid comentario de la sentencia en HuNTER, «A more modern Crown», cit., 2012, pp. 444-446.

149 Teskey v. Canada (Attorney General), Sentencia de la Corte de apelaciones de 26 de agosto de 2014.

150 Referencias detalladas en Cornell, «Succesion to the Throne», cit., 2015, pp. 201-204.

151 Vid. Ministére de la Justice (Quebec), Extraits des rôles d'audience, mayo de 2015; CANAdian Broadcasting Corporation, «Royal Baby Bill Challenge Joined By Quebec Attorney General», Huffington Post, de 22 de julio de 2013.

152 Sentencia de la Corte Superior de Quebec, caso Motard v. Procureur general du Canada et al., número 200-17-018455-139, 2016 QCCS 588.

153 Vid. «Deux profs de l'Universitè Laval d’boutés dans la cause du «bébé royal»», Le Soleil, 16 de febrero de 2016.

154 SÈGuIN, «La cause du «bébé royal» en appel», Le Soleil, 15 de marzo de 2016. 
nacer varón el tercer hijo que en la actualidad esperan los Duques de Cambridge, se produciría una situación compleja, ya que en Canadá este tercer hijo precedería en la línea de sucesión a su hermana Carlota —aunque no en el resto de los Reinos de la Commonwealth.

\section{La reforma de la sucesión al trono en los Reinos del Caribe}

Inicialmente los gobiernos de Jamaica y Belice expresaron que sus constituciones dejaban las normas de la sucesión al trono a la legislación del Reino Unido, y que no era necesaria una reforma a menos que sus parlamentos expresasen otra $\operatorname{cosa}^{155}$. Los gobiernos de Antigua, Barbados, Bahamas, Granada, Santa Lucía, San Vicente y las Granadinas y San Cristóbal y Nieves, por su parte, también expresaron una opinión similar, aunque indicaron que analizarían cual era la mejor forma para dar efecto a los cambios. En la práctica, San Cristóbal y Nieves, San Vicente y las Granadinas y Barbados ${ }^{156}$ tramitaron sus leyes de asentimiento respectivas, con algunos matices que las diferencian ligeramente. Antigua y Barbuda ${ }^{157}$, las Bahamas, Belice, Granada y Jamaica, por su parte, concluyeron que no era necesario tramitar ninguna norma para adherirse a la reforma realizada en el Reino Unido. Vamos a exponer los detalles, refiriéndonos en primer lugar a las Bahamas y Belice, y a continuación a los llamados Reinos de las Indias Occidentales.

La Mancomunidad de las Bahamas (Commonwealth of Bahamas) está constituida por más de setecientas islas, cayos e islotes, aunque poco más de una veintena están habitados. Las Bahamas, inicialmente colonizadas por los españoles, se convirtieron en una colonia británica en 1718 y obtuvieron la independencia como Monarquía parlamentaria el 10 de julio de 1973. La Constitución de Las Bahamas inviste de autoridad ejecutiva a su Majestad, pero no define quién es tal persona, habiendo de acudirse a la llamada The Babamas Interpretation Act. De esta norma se deduce que las normas de sucesión al Trono del Reino Unido que estaban vigentes el 10 de julio de 1973 quedaron incorporadas a su ordenamiento a través de la referencia que de ellas hace la Constitución. De cara a la implementación del Acuerdo de Perth cabían dos posibilidades. La primera pasaba por interpretar que los cambios en las normas de sucesión requerían una reforma constitucional en sentido estricto, con mayoría cualificada de tres cuartos y referéndum; la segunda posibilidad, en cambio, implicaba aceptar que las normas incorporadas mediante

155 Tal y como se recoge en el documento Parlamentary Debates, House of Lords, col. 310, intervención de Lord Wallace de TANKeRness, impulsor de la norma de reforma de la sucesión al trono en la Casa de los Lores, el 13 de marzo de 2013. Accesible en publications.parliament.uk.

$156 \mathrm{El}$ titulo de la norma es: An Act to provide for the Parliament of Barbados to acquiescence to alterations in the law relationg to the succession to the Throne of the United Kingdom, Government Information Service, Bridgeton, 2015, disponible en www.barbadosparliament..com.

157 Tankerness, Parlamentary Debates, House of Lords, col. 1228. 
referencia tenían un rango de legislación ordinaria y podían ser reformadas como tales. Belice, por su parte, evolucionó a partir de la que se conociera como Honduras Británica, que comprendía también las Islas de la Bahía (en la actualidad territorio de Honduras) y la Mosquitita (en la actualidad dividida entre Honduras y Nicaragua). Fue una colonia de la Corona entre 1871 y 1964, cuando obtuvo un margen de autogobierno, y obtuvo su independencia en 1981. En su Constitución se reconoce autoridad ejecutiva a «Su Majestad», si bien no precisa lo que por tal ha de entenderse ni recoge previsión alguna sobre la sucesión a la Corona. No obstante, la doctrina interpretó, y así lo entendió también el gobierno, que no era necesaria ninguna actuación para que la reforma realizada en Westminster tuviera efectos en la sucesión a la Corona de Belice.

Por cuanto se refiere a los demás reinos del Caribe, entre los años 1958 y 1962 las colonias británicas del Caribe ${ }^{158}$ se asociaron en la llamada Federación de las Indias Occidentales (West Indies Federation) o Federación de Antillas, bajo la British Caribbean Federation Act. Esta federación dejó de existir cuando se separaron de ella los dos estados más grandes de dicho conjunto: Jamaica, y Trinidad y Tobago. En ese momento el Parlamento del Reino Unido disolvió la Federación, mediante la Ley de las Indias Occidentales, y el resto pasó a tener un estatus como colonias autónomas bajo la directa supervisión de Londres. Tiempo después, la mayoría de ellas alcanzó la independencia ${ }^{159}$ (así, Barbados en $1966^{160}$, Granada en 1974, Dominica en 1978, Santa Lucía en 1979, San Vicente y Las Granadinas en 1979, Antigua y Barbuda en 1981 y San Cristóbal y Nieves en 1983). Sin perjuicio de que aspectos clave de su historia y su arquitectura institucional las diferencien, las Constituciones de estos siete Reinos invistieron de autoridad ejecutiva a «Su Majestad» y establecieron que el Parlamento consistiría en Su Majestad y una o dos cámaras ${ }^{161}$. Para establecer quién ha de entenderse por «Su Majestad», no es posible hallar referencias en los textos constitucionales, sino que ha de recurrirse, en unos casos, a la $U K$ Interpretation Act de 1889 (en Granada, Jamaica y Santa Lucía) y, en otros, a la Interpretation Act de 1978 (en Antigua y Barbuda, San Cristóbal y Nieves, y San Vicente y las Granadinas). Dado que como consecuencia de los procesos de independencia el Parlamento de Westminster perdió autoridad para legislar con efectos para estos Reinos $^{162}$, en la implementación del Acuerdo de Perth se planteaban dos posibles interpretaciones: la primera, que quien sucediera al Rey o Reina de la Gran

158 Antigua y Barbuda, Barbados, Dominica, Granada, Jamaica (incluyendo las Islas Caimán y las Islas Turcas y Caicos), Montserrat, Trinidad y Tobago, San Cristóbal y Nieves (incluyendo Anguila), Santa Lucía y San Vicente y las Granadinas.

159 Montserrat, las Islas Caimán e Islas Turcas y Caicos (separados de Jamaica) y Anguila (separado de San Cristóbal y Nieves) se han mantenido como Territorios Británicos de Ultramar (British Overseas Territories).

160 BeCKles, A History of Barbados: From Amerindian Settlement to Caribbean Single Market, Cambridge University Press. 2007, pp. 1-6.

161 Philipps, Commonwealth Caribbean Constitutional Law, Cavendish, 2002, p. 208-2012.

162 Hunter, «A more modern Crown», cit., 2012,p. 457. 
Bretaña sería también Rey o Reina de los respectivos reinos; la segunda, que la sucesión al trono de cada Reino quedaría regida por sus propias normas sucesorias. Esta segunda opción, a su vez, llevaba a discutir si para implementar el Acuerdo de Perth sería o no necesario proceder a reformas constitucionales con mayoría cualifi$\operatorname{cada}^{163}$ — quizás incluso con un posterior respaldo en referéndum ${ }^{164}$ _, o si era posible una reforma en la legislación ordinaria. Finalmente, y con excepción de Barbados, todos estos Reinos entendieron que la UK Interpretation Act y la Interpretation Act podían ser objeto de reforma ordinaria en sus respectivos parlamentos ${ }^{165}$. Algo diferente fue el caso de Barbados. Barbados alcanzó su independencia en noviembre de 1966, mediante la Barbados Independence Act, momento a partir del cuál cesó la capacidad del parlamento de Westminster para legislar con efectos para dicho país. Al igual que sucede en otros reinos del Caribe, la Constitución de Barbados $^{166}$ no definió quién es «Su Majestad», pero la Barbados Interpretation Act de 1975, elaborada con el propósito de interpretar la Constitución, establece que la expresión «Su Majestad» incluye a su Majestad la Reina y a sus herederos y sucesores $^{167}$. En cualquier caso, y en términos prácticos, el proceso fue muy similar a los mencionados porque se consideró que era posible reformar las normas de la sucesión al trono mediante una reforma legislativa ordinaria ${ }^{168}$.

Como apunte final, y en relación con la cuestión republicana, algunos autores sostienen que en la actualidad no todos los ciudadanos de estas regiones de Caribe perciben ya la mística de una Reina Ausente. Durante bastante tiempo la jefatura de Estado fue vista como un símbolo de unidad en un contexto político polarizado ${ }^{169}$ - en algunos casos con importantes niveles de tensión internos. Se veía en el Monarca un rol que puede poner en juego su influencia y buen hacer en los casos en que fuera necesario, pero esa visión está evolucionando. De hecho, en el momento de la adopción del Acuerdo de Perth, Granada y Jamaica se estaban planteando ser repúblicas. En 2010 se presentó en Granada un borrador de constitución republicana y en Jamaica y Barbados se barajó la posibilidad de tal reforma en la celebración de 50 aniversario de la independencia del país. En ambos casos la reforma requeriría una mayoría cualificada en los parlamentos y una aprobación en referéndum por mayoría simple en Jamaica y cualificada de dos tercios en Granada, pero a la fecha de publicación de este escrito no se han producido avances en esa dirección. Drayton expresaba recientemente que ${ }^{170}$ cin-

163 De dos tercios en cada una de las cámaras en la mayor parte de dichos Reinos, y de tres cuartas partes en el caso de Santa Lucía.

164 Por mayoría de dos tercios en San Cristóbal y Nieves, y mayoría simple en Jamaica y Santa Lucía.

165 HunTER, «A more modern Crown», cit., 201 2,p. 458.

166 Barbados Constitution, LRO, 2002, secciones 35, 65.

167 Barbados Interpretation Act, LRO 1978, c1, sección 10 (1)-(2).

168 En opinión de HunTer, «A more modern Crown», cit., 2012, p. 460.

169 Phillips, Commonwealth Caribbean Constitutional Law, cit., 2002, pp. 335-336.

170 Drayton, Whose Constitution? Law, Justice and History in the Caribbean, Judicial Education Institute, Sixth Distinguished Lecture, 2016, pp. 27-28. 
cuenta años después de su independencia, los países del Caribe quizá deberían asumir un rol propio de padres y madres fundadores de sus sistemas políticos, procediendo a una segunda descolonización en la que se revisen las decisiones incompletas que fueron adoptadas en los años setenta. Pero más allá de algunas opiniones doctrinales o expresadas por algunos cargos políticos puntuales, lo cierto es que hasta la fecha no se ha producido ningún movimiento significativo en este sentido ${ }^{171}$.

\section{REFLEXIONES FINALES}

La norma de reforma de la Sucesión al Trono propuesta por el Reino Unido fue deliberadamente concisa, porque el Gobierno británico y los del resto de Realms deseaban evitar que su tramitación diera pie a reformas constitucionales más profundas. De hecho hemos visto que en algunos países, como Canadá, se acudió a convenciones constitucionales no escritas para justificar que el Parlamento federal asumiera un rol exclusivo y evitar así los inconvenientes de un proceso en el que, por la participación de las diez provincias — especialmente de Quebec-, pudieran producirse dilaciones no deseadas. También se omitió deliberadamente entrar la cuestión de la posibilidad de que un católico fuese heredero al trono (algo que la suma de la Declaración de Derechos, el Acta de Establecimiento de 1701, el Acta de la Unión de 1707 y el acta de Declaración en el Acceso de forma cumulativa impiden $)^{172} \mathrm{o}$ en el rol del monarca en la Iglesia Anglicana del siglo XXI. Como ya se ha explicado, existía un convencimiento de que la operación debía realizarse con precisión casi quirúrgica, sin dar pie ni tiempo a mayores complicaciones. Con la excepción de Canadá, donde está pendiente de finalización un recurso de inconstitucionalidad, parece que ese objetivo se consiguió respecto del resto de los Realms.

La monarquía — no necesariamente constitucional— fue un modelo predominante en la Europa Occidental hasta 1914. Sólo tres países, Francia, Portugal y Suiza, se habían constituido en aquella época como Repúblicas ${ }^{173}$. Desde los años 80, sin embargo, sólo está presente en Bélgica, Dinamarca, España, Luxemburgo, Noruega, Países Bajos, Reino Unido y Suecia, a los que se añaden los Principados de Mónaco y Liechtenstein. Tras la reciente reforma en el Reino Unido, en Europa sólo en España, Mónaco y Liechtenstein sigue en vigor la preferencia del varón sobre la mujer. Pero no es ésta la característica más significativa de la monarquía británica. Si en términos comparativos la preservación de la

171 Benedictus, «After Barbados, who will be next to give the Queen her marching orders?», The Guardian, marzo de 2015.

172 PAPWORTH, cit., pp. 1091-1093.

173 Bogdanor, «European Constitutional Monarchs», ButLER/ Low (eds.), Sovereigns and Surrogates, cit., 1991, pp. 274-275. 
institución monárquica llama la atención en el panorama internacional —apenas una treintena de los países democráticos son Monarquías ${ }^{174}$ _, qué decir del hecho de que de ese pequeño conjunto, en torno a la mitad de los Estados compartan a la misma Reina (Isabel de Windsor) ${ }^{175}$. Un fenómeno sin precedentes, llamativo en sí mismo y también en tanto simboliza que en su adaptación a los tiempos ${ }^{176}$. En el proceso de descolonización el Reino Unido de la Gran Bretaña y Norte de Irlanda no sólo supo mantener sus lazos con las antiguas colonias sino que dio paso, a partir de la Declaración de Londres, a una importante organización internacional, que se extiende a prácticamente todas las regiones geográficas y es diversa en religiones y culturas.

La Oficina de los Dominios se transformó en Oficina de Relaciones de la Mancomunidad de Naciones en 1947 y pasó a ser Oficina de Asuntos Exteriores y de la Mancomunidad en 1966, y de cuatro miembros la Mancomunidad pasó a estar formada por más de cincuenta países independientes, la mayoría de ellos repúblicas ${ }^{177}$. Es difícil reconocer qué le da unidad a una entidad tan extraña como la Commonwealth sin enfatizar el rol, con el paso del tiempo cada vez más simbólico, que aún desempeñan en ella el Reino Unido y su longeva Monarca ${ }^{178}$. Se ha dicho que resulta tan fácil exagerar la contribución de la Monarquía a estos procesos como minimizarla a favor de otras instituciones, pero parece que la verdad está en algún lugar intermedio ${ }^{179}$. Simbólico o no, el rol de la Corona, o de la propia Isabel II, en la cimentación de la Mancomunidad moderna e incluso en la tarea de neutralizar los sentimientos nacionalistas en las antiguas colonias ha sido crucial en algunos momentos del proceso de descolonización y construcción constitucional de los nuevos Estados ${ }^{180}$. En la actualidad siguen siendo muchas las diferencias sociopolíticas, económicas y culturales que separan a los antiguos Dominios de Canadá, Australia, y Nueva Zelanda, con 36, 24, y casi cinco millones de habitantes respectivamente, de pequeños Reinos como los de Granada (cien mil habitantes), San Cristóbal y Niveles (cincuenta mil) o Tuvalú (once mil). Al menos en teoría, y dado que se trata de Coronas separadas, es posible en hipótesis que los consejos que recibe cada Reino de su Monarca sean diferentes y discrepantes entre sí, pero lo cierto es que el hecho de tratarse de una misma persona ha contribuido a que se ofrezcan consejos armónicos y en

174 Junto a los 16 Realms de la Commonwealth y las citadas Monarquías Europeas, se cuentan también entre las Monarquías democráticas las de países como Bahrein, Lesotho, Jordania, Camboya, Malasia o Japón.

175 Boyce, The Queen's Other Realms. The Crown and Its Legacy in Australia, Canada and New Zealand, The Federation Press, 2008, p. 1.

176 Forman, «Redefining the Monarchy and the Crown», Constitutional Change in the UK, $12^{\mathrm{a}} \mathrm{ed}$, 2002, p. 186.

177 BuTLER, «Introduction», Butler/ Low (eds.) Sovereigns and Surrogates, cit., 1991, pp. 1-2.

178 Jennings, The British Constitution, cit., 1971, p. 122.

179 Jennings, The British Constitution, cit., 1971, p. 121.

180 Vid. Cando Somoano, «La posición de la Corona», cit., 2000, pp. 109 y ss, 117 y 125. 
beneficio de todos los miembros de la Mancomunidad ${ }^{181}$. De hecho, y según los expertos es previsible que en los próximos años, y como consecuencia del BrExit, el Reino Unido de la Gran Bretaña y Norte de Irlanda refuerce a la Commonwealth, por cuanto ésta puede aportarle estratégicamente tras su salida de la Unión Europea. Quizá se produzcan, quien lo sabe, nuevos hitos en la evolución de esta organización internacional.

La continuidad de la monarquía a lo largo de la historia ha proporcionado estabilidad a las instituciones y a la estructura social ${ }^{182}$, pero no sólo no ha impedido el progreso sino que ha patrocinado y amparado la evolución, siendo esa la razón de su larga supervivencia ${ }^{183}$. Ha sido así aunque se insista en que una república parecería una forma de gobierno más acorde con los tiempos que vivimos. Coincidimos con Bogdanor ${ }^{184}$ en que sería estéril especular sobre si la monarquía constitucional es o no una buena forma de gobierno, porque lo que es claro es que a día de hoy se ajusta al temperamento británico y forma parte del concepto que se tiene sobre lo que supone ser británico ${ }^{185}$. A ello ha de sumarse que la monarquía británica a lo largo de los siglos ha demostrado su capacidad para modernizarse y adaptarse a los tiempos sin que por ello se produzca un daño significativo en la estructura y las convenciones sobre las que se asienta ${ }^{186}$. Entre los retos más importantes que ha asumido, sin duda, está el de permanecer y adaptarse a un escenario de descolonización, generando un nuevo espacio de entendimiento entre la antigua metrópoli y sus territorios en el que, incluso con las repúblicas, el vínculo se mantiene sobre la idea de la lealtad común a la Corona.

Y si respecto de los Realms parece improbable un cambio drástico, qué decir respecto de la Jefatura de la Mancomunidad de Naciones. Ninguna previsión constitucional $^{187}$, se ha dicho ya, explica porqué Isabel de Windsor sigue siendo la Jefa de la Mancomunidad de Naciones ${ }^{188}$. Los expertos lo atribuyen al respeto que se le expresa, más a sentimientos incluso que al intelectoo ${ }^{189}$. Y quizá por ello existe una cierta preocupación por que el primero de quienes le suceden, el Príncipe Carlos de Gales, está lejos de concitar semejante adhesión ${ }^{190}$. Esta por ver, por tanto, qué nos deparará el futuro.

181 BARKer, La monarquía constitucional de la Gran Bretaña, Oxford University Press, 1943, p. 29.

182 Ibídem Fernández Fontecha/ Pérez de Armiñán, La Monarquía y la Constitución, Civitas, Madrid, I987, p. 63.

183 BARKer, La monarquía constitucional de la Gran Bretaña, Oxford University Press, 1943, pp. 19-20.

184 Bogdanor, The Monarchy and the Constitution, cit., 1995, p. 300.

185 Bogdanor, «United Kingdom», Butler/ Low (eds.), Sovereigns and Surrogates, cit., 1991, p. 10, 37.

186 SCruton, England, an Elegy, Chatto \& Windus, Londres, 2000, p. 3.

187 Boyce, The Queen's Other Realms, cit., 2008, 7.

188 Murphy, Monarchy and the End of Empire, cit., 2015, p. xi.

189 Bogdanor, Barnett, The Power and the Throne: The Monarchy Debate, Vintage, Londres, 1994, p. 193.

190 Mansillo, «Loyal to the Crown», cit., 2016, pp. 213-235, 235. 
$* * *$

TITLE: The Reform of the Succession to the Crown in the United Kingdom of Great Britain And Northern Ireland, and in the «other Kingdoms» of the Commonwealth of Nations.

Summary: The United Kingdom of Great Britain and Northern Ireland shares a Monarch with fifteen other Realms of the Commonwealth of Nations, in a phenomenon that is described as "sixteenth separated Crowns in personal union». Since the 1970s or earlier reference had been made to the need to adapt the laws of succession to the principles of gender equality and religious freedom expressly or implicitly recognised in the Kingdoms at a constitutional level. However, reasons of expediency bad resulted in resistance to such reforms. Amongst these are the delicate balance which underpins the monarchic institution, both in these States and in the Commonwealth as a whole, as well as the fact that three Protestant males are the first in line to succeed the long-living Elizabeth of Windsor. The engagement and subsequent marriage of the Duke and Duchess of Cambridge was what triggered the reform process, promoted via the Perth Agreement at the Conference of Commonwealth Heads of Government Meeting (CHOMG) in October 2011. This work addresses the complexity involved in the reform of a corpus of legislation dating back to the 18th century but which has seen how with the passage of time the reality upon which it is projected, the British Crown, has evolved into sixteen separate Crowns linked to a Community of Nations formed by over 50 States, most of them republics. There is detailed analysis of a process in which questions of both political expediency and difficulties of legal interpretation have played their part. As will be seen, the socio-political and cultural particularities specific to some of the Realms, such as the federal realities or the uniqueness of Quebec in Canada, explain why the process of implementation of the aforementioned Agreement extended into the year 2015.

Resumen: El Reino Unido de la Gran Bretaña comparte Monarca con otros quince Reinos de la Mancomunidad de Naciones (Commonwealth of Nations), en un fenómeno que es descrito como «dieciséis Coronas separadas, aunque en unión personal». Desde al menos los años 70 se había venido apuntando la necesidad de adaptar las normas de sucesión a los principios de igualdad de género y libertad religiosa, expresa o implícitamente reconocidos en los Reinos a nivel constitucional. Sin embargo, razones de oportunidad habian venido oponiendo resistencia a la reforma. Entre esas razones, están el delicado equilibrio sobre el que la institución monárquica se asienta, tanto en dichos Estados como en el conjunto de la Commonwealth, así como el hecho de que tres varones protestantes ocupaban los primeros puestos en la sucesión de la longeva Isabel de Windsor. El compromiso y posterior matrimonio de los Duques de Cambridge fue lo que desencadenó el proceso de reforma, impulsado mediante Acuerdo de Perth en la Conferencia de Jefes de Gobierno de la Commonwealth en octubre de 2011. El presente trabajo aborda la complejidad de proceder a la reforma de un conjunto normativo originario del siglo XVIII pero que ha visto cómo con el paso de los siglos la realidad sobre la que se proyecta, la Corona Británica, ha evolucionado hacia dieciséis Coronas separadas y vinculadas a una Mancomunidad de Naciones conformada por más de 50 Estados, la mayoría de ellos repúblicas. Se analizará en detalle un proceso en el que han tenido protagonismo tanto cuestiones de oportunidad política, como difcultades de interpretación normativa. Como se verá, las particularidades sociopolíticas y culturales específicas de algunos de los Reinos, entre ellas las realidades federales o la especificidad de Quebec en Canadá, explican porqué el proceso de implementación del citado Acuerdo se prolongó hasta entrado el año 2015.

KeY wORDS: Commonwealth, Commonwealth Realms, Realms, United Kingdom, Crown, Monarchy, Succession to the Throne.

Palabras Clave: Mancomunidad de Naciones, Reinos de la Mancomunidad de Naciones, Reino Unido, Corona, Sucesión al Trono.

FECHA DE RECEPCIÓN: 10.12.2017

FECHA DE ACEPTACIÓN: 01.02.2018 
